\title{
Urbanização e produção de cidades no/do Território de Identidade Portal do Sertão
}

\author{
Urbanization and production of cities in/of the Territory of Identity \\ Portal do Sertão
}

\begin{abstract}
Janio Santos
\section{RESUMO}

Este texto se propõe a pensar, com base Território de Identidade Portal do Sertão, as características da sua dinâmica urbano-regional e refletir sobre os fatores que influenciaram as transformações na lógica da urbanização e como essas favoreceram a criação e consolidação dos núcleos urbanos. Além de reflexões teóricas, as análises fundamentam-se em pesquisa documental, investigação de campo e mapeamento das informações coletadas. A partir de 1960 e, principalmente, de 1970 e 1980, esse território de identidade passou por mudanças profundas na lógica da urbanização, engendradas por alterações dos/nos processos de urbanização brasileiro e baiano. De modo geral, elas estão vinculadas às transformações na dinâmica econômica e em novos arranjos políticos que influenciaram as características sociodemográficas da região, bem como têm relação com a expulsão do homem do espaço rural, seja via modernização da agricultura, crise na economia agrícola ou ausência de políticas voltadas à permanência no campo. O processo impactou na formação de vários núcleos urbanos e na paulatina firmação da dinâmica urbana como determinante para a organização do espaço do Portal do Sertão.
\end{abstract}

Palavras-chave: Portal do Sertão, Dinâmica urbana, Urbanização

\section{ABSTRACT}

This text analyzes the characteristics of the urban and regional dynamics of the Territory of Identity Portal do Sertão and reflects the factors that influenced the transformations in urbanization and how these favored the creation and consolidation of the urban nuclei. The analysis are based on theoretical reflections, documentary research, field research and mapping. From 1960, mainly from the 1970s and 1980s, this territory of identity had its urbanization logic modified as result of changes in the processes of urbanization in Brazil and Bahia. In general, they are connected to changes in the economic dynamics and new political arrangements that influenced the socio-demographic characteristics of the region. This is also related to the expulsion of man from the countryside because there has been modernization of agriculture, crisis in the agricultural economy or absence of policies of permanence in the countryside. he process formed numerous urban centers and established over time the urban dynamics as determinant for the organization of the Portal do Sertão.

Keyswords: Portal do Sertão, Urban dynamics, Urbanization

'Professor Pleno da Universidade Estadual de Feira de Santana, Feira de Santana, BA. E-mail: janiosantos@yahoo.com.br Orcid-ID: https://orcid.org/0000-0003-0730-1271 


\section{INTRODUÇÃO}

Nas quatro últimas décadas, são observadas profundas transformações nas cidades baianas, como consequência de alterações que se desdobraram em várias escalas. O Estado da Bahia consolidou-se como uma Unidade Federativa majoritariamente urbana, produto de novas relações de trabalho e de produção que foram engendradas durante todo o século $X X$, e novos aspectos da vida e dinâmica das cidades passaram a fortalecer a lógica urbana.

Com base nos argumentos supramencionados, desenvolve-se estas reflexões com vistas a pensar, com base Território de Identidade Portal do Sertão, quais são as características da sua dinâmica urbana, no sentido de conjecturar os fatores que influenciaram as transformações na urbanização e, por seu turno, como essas favoreceram à criação de núcleos urbanos, em particular, Feira de Santana, o centro principal; diversas cidades pequenas; e áreas menores, como vilas e outros aglomerados. A meta é entender os elementos que determinam o conteúdo da urbanização como produto de lógicas sociais, políticas e econômicos e verificar, na atualidade, as implicações na estruturação das áreas urbanas nele localizadas.

Tais aspectos fazem parte das discussões desenvolvidas no Grupo de Pesquisa Urbanização e Produção de Cidades na Bahia, constituído por investigações que são realizadas sobre algumas áreas urbanas do Estado. Foram avançar nas reflexões sobre os processos e dinâmicas que ocorrem na escala intraurbana, essa sistemática tem o propósito de fortalecer o debate sobre as áreas urbanas baianas e contribuir com novas ponderações sobre as mudanças no processo de urbanização, oriundas das verificações empíricas.

Fora as ponderações teóricas, estas análises são fundamentadas em pesquisa documental, bem como investigação de campo e mapeamento das informações coletadas. O texto está organizado em três seções: a primeira analisa os determinantes da urbanização e sua relação com o Território de 
Identidade Portal do Sertão; a segunda, as mudanças na composição das cidades no referido espaço regional; e por final, os traços mais atuais da dinâmica urbana.

\section{URBANIZAÇÃO PRETÉRITA DO PORTAL DO SERTÃO}

O tema em tela está relacionado ao fato de que o processo de urbanização contemporâneo sofreu forte influência das mudanças ocorridas a partir do século XVIII, em função da Primeira Revolução Industrial, bem como de outros câmbios decorrentes desse fenômeno, ainda no século XIX, como alterações no sistema de circulação e comunicação. O que se verificou, após esse contexto, foi um contundente e paulatino amadurecimento do capitalismo no mundo, segundo Santos (2013).

Fundamentado por Sposito (2004), salienta-se a necessidade de evitar, na Geografia, a adoção do termo urbanização de forma reducionista, como sinônimo de dotação de infraestrutura urbana, crescimento da população urbana ou associado ao aumento na Taxa de Urbanização, dentre outras expressões. Com base em Lefebvre $(2004,2008)$, adota-se a ideia da urbanização como um processo, o que implica num movimento que se desdobra num interregno de tempo, e a cidade como a própria materialidade da urbanização e que dialeticamente a influencia, algo discutido outrora (SANTOS, 2013). Sua complexidade só pode ser apreendida com base na discussão sobre as múltiplas transformações que ocorreram na relação entre a Sociedade e a Natureza ao longo da história, o que pressupõe uma divisão técnica, social e territorial do trabalho.

A ascensão do modo capitalista de produção foi um registro relevante para a urbanização mundial. A apropriação da natureza e sua conversão em mercadoria são, portanto, indícios de que o espaço foi reconfigurado e 
4 | Urbanização e produção de cidades no/do Território de Identidade Portal do Sertão

(des)configurado em sincronia com a veleidade do processo de reprodução do capital, acentuada com a Primeira Revolução Industrial, ainda no século XVIII. Contudo, a industrialização foi apenas propulsora da urbanização contemporânea e sobrelevou o papel das cidades. Portanto, uma contradição central, pois a industrialização é, ao mesmo tempo, um produto e uma condição da urbanização, sendo essa última um fenômeno que transpassa o tempo, o que coloca aquela como um momento do processo geral.

Faz-se necessário diferenciar a urbanização, na fase anterior ao capitalismo, da ocorrida após a consolidação do referido modo de produção. No primeiro momento, tendo como expressão o fenômeno da urbanização sucedido nos períodos imperiais, principalmente no Império Romano, e na Idade Média, com a expansão comercial, percebe-se que às cidades desempenhavam, respectivamente, papel enquanto espaço voltado para articular as funções de administração e de exploração tributária à vida no campo, a partir da ascensão das cidades-estado; e seu "arrefecimento" político, no período feudal, com a presença das cidades eclesiásticas e dos burgos (MUNFORD, 1961). No segundo, principalmente após a Primeira Revolução Industrial, a cidade passou a ser o centro de produção, gestão, circulação e realização da mais-valia. Os norteadores da urbanização foram seu espraiamento em nível mundial, a formação de novas estruturas urbanas e a redefinição da divisão do trabalho social, técnica e territorial.

No caso brasileiro, é preciso compreender que a urbanização abalizou quase toda trajetória da sua formação socioespacial, isso a partir século XVI, início do Período Colonial. Significa considerar que a urbanização e, consequentemente, a produção de cidades foram marcadas, a grosso modo, por dois grandes períodos: 
O primeiro, denominado por Santos (1993) urbanização pretérita, assinala a formação das primeiras cidades e vilas, dentre outros aglomerados menores, e que perdurou até o início do século XX. São traços dessa fase, sobretudo nos primeiros séculos: baixa articulação entre áreas urbanas; baixa densidade técnica incorporada ao território; nível menor da capacidade produtiva das áreas urbanas; espacialidades urbanas mais compactas; e forte incidência das dinâmicas rural e agrícola nos determinantes da vida cotidiana nas cidades, em particular as decisões políticas.

O segundo está diretamente relacionado ao processo de industrialização ${ }^{1}$ que ocorreu no Brasil, sobretudo após a década de 1940, quando um fenômeno político, social e econômico mudou categoricamente a cidade e, sobretudo, a forma como sua produção passou a engendrar-se. Nesse contexto, os traços mais marcantes são: maior articulação entre as áreas urbanas; maior densidade técnica incorporada ao território; alta capacidade produtiva das cidades, mormente as metrópoles; espacialidades urbanas mais extensas e dispersas; e ascensão da burguesia urbano-industrial como determinante da vida social e política, inclusive, que incide sobre as dinâmicas rural e agrícola, com profundas redefinições no cotidiano das cidades.

É importante considerar que a sistemática supracitada não é estanque, tampouco se desenvolve sem ponderar que o interregno entre o século XIX e início do XX foi um período de acentuadas transições no contexto da urbanização brasileira. Portanto, a depender do contexto regional que se trata ou mesmo da cidade sob julgo, diferentes níveis de consolidação de mudanças e permanências demarcam o modo com as áreas urbanas e as dinâmicas sociais, políticas e econômicas eram colmatadas.

Isso reitera o fato de que, no Brasil, a hegemonia do capitalismo incidiu nas cidades e alterou seu conteúdo e estrutura urbana, mesmo no início do século 
XX. Entretanto, foi a partir da década de 1940 que o país passou por mudanças mais profundas na urbanização, processo desencadeado, principalmente, pela instauração da nova conjuntura política e econômica sobredita. A implantação da política industrial, que teve como suporte principal o Estado, coadunado com capitais privados nacionais e internacionais, constitui-se em um modelo extremamente concentrador, na medida em que privilegiou a Região Sudeste, no início da implantação, sobretudo São Paulo, em função das condições infraestruturais mais favoráveis.

$\mathrm{Na}$ época da industrialização, entretanto, ocorreu maior articulação entre o Sudeste e as demais regiões brasileiras, principalmente, em função dos investimentos estatais em infraestrutura de circulação entre as regiões, sobremaneira, em estradas de rodagem. O objetivo desses investimentos foi articular a região industrializada às demais do país, face à necessidade de constituir um mercado consumidor nacional para a produção industrial, fato que redefiniu a divisão social, técnica e territorial do trabalho em escala nacional e, por sua vez, alterou as atividades produtivas no interior de cada região.

Ao analisar os elementos que influenciam a materialização das cidades na sociedade contemporânea, Santos (2013) argumenta que se está sob a égide de uma urbanização cuja complexidade é maior, sem querer dizer que, anteriormente, essa não obtivesse certo grau de complexidade. Assim, afirma-se que, na atualidade, em função de diversos aspectos, há a superposição de processos e dinâmicas, que, por sua vez, decorrem em alterações profundas no modo como os espaços urbanos são estruturados.

O Território de Identidade Portal do Sertão foi delimitado em função de uma nova regionalização proposta pelo Governo do Estado da Bahia, elaborada a partir de 2007, a qual foi redefinida em 2013, cuja discussão teórica não faz parte dos interesses deste texto (SEPLAN, 2013). Parte da área está contida no Polígono 
das Secas, situada num eixo de transição entre o agreste e a caatinga. Três importantes rodovias federais, a BR-101, a BR-116 e a BR-324, e outras rodovias estaduais, tais como a BA-504, BA-411, BA-120, BA-515 e BA-084, constituem os eixos de articulação entre o espaço regional e outras áreas da Bahia e do Brasil (Figura 1), as quais têm Feira de Santana como cidade polo e considerada pelo IBGE (2017) como maior entroncamento rodoviário do Norte-Nordeste.

Segundo dados levantados pelo IBGE (1958a, 1958b), diferentes aspectos assinalam o povoamento dos municípios que fazem parte, hoje, do Território de Identidade Portal do Sertão². Três etnias indígenas marcaram a ocupação anterior à invasão portuguesa às terras da América, que são os Tupi, Kariri e Botocudo. Nas porções norte-nordeste e central há registros que mencionam a ocupação de tribos tapuias, aimorés e paiaiás. Como trata-se de uma ampla extensão territorial, não se pode dizer que todas as áreas que deram origem às cidades desse Território de Identidade tiveram, necessariamente, a presença indígena, principalmente em seus sítios urbanos. Entretanto, a ocupação de cidades como Santa Bárbara, Irará, Anguera e Água Fria, por exemplo, deu-se com base em conflitos entre os bandeirantes, assassinos que marcaram a história da posse da terra na Bahia, e as tribos locais.

As ocupações portuguesas de partes desse Território ocorreram, nomeadamente, a partir do final do século XVI e início do XVII. A lógica das sesmarias, sobretudo ante o parcelamento das terras da família Garcia D'Ávila, mas também de doações do Governo Geral do Brasil à João Peixoto Viegas e aos irmãos Luiz Vaz e Manoel Nunes Paiva, por exemplo, são aspectos importantes para compreender o povoamento da região (IBGE, 1958a, 1958b). De forma geral, três itens definem o inicial aproveitamento das terras do Portal do Sertão para atividades produtivas: o avanço da criação de gado, nas porções central e 
8 | Urbanização e produção de cidades no/do Território de Identidade Portal do Sertão

nordeste; a implantação de engenhos de cana de açúcar, mais ao sul e sudeste; e o uso das águas do Rio Paraguaçu, na parte mais a oeste.

Figura 1- Delimitação do Território de Identidade Portal do Sertão, Bahia, 2019
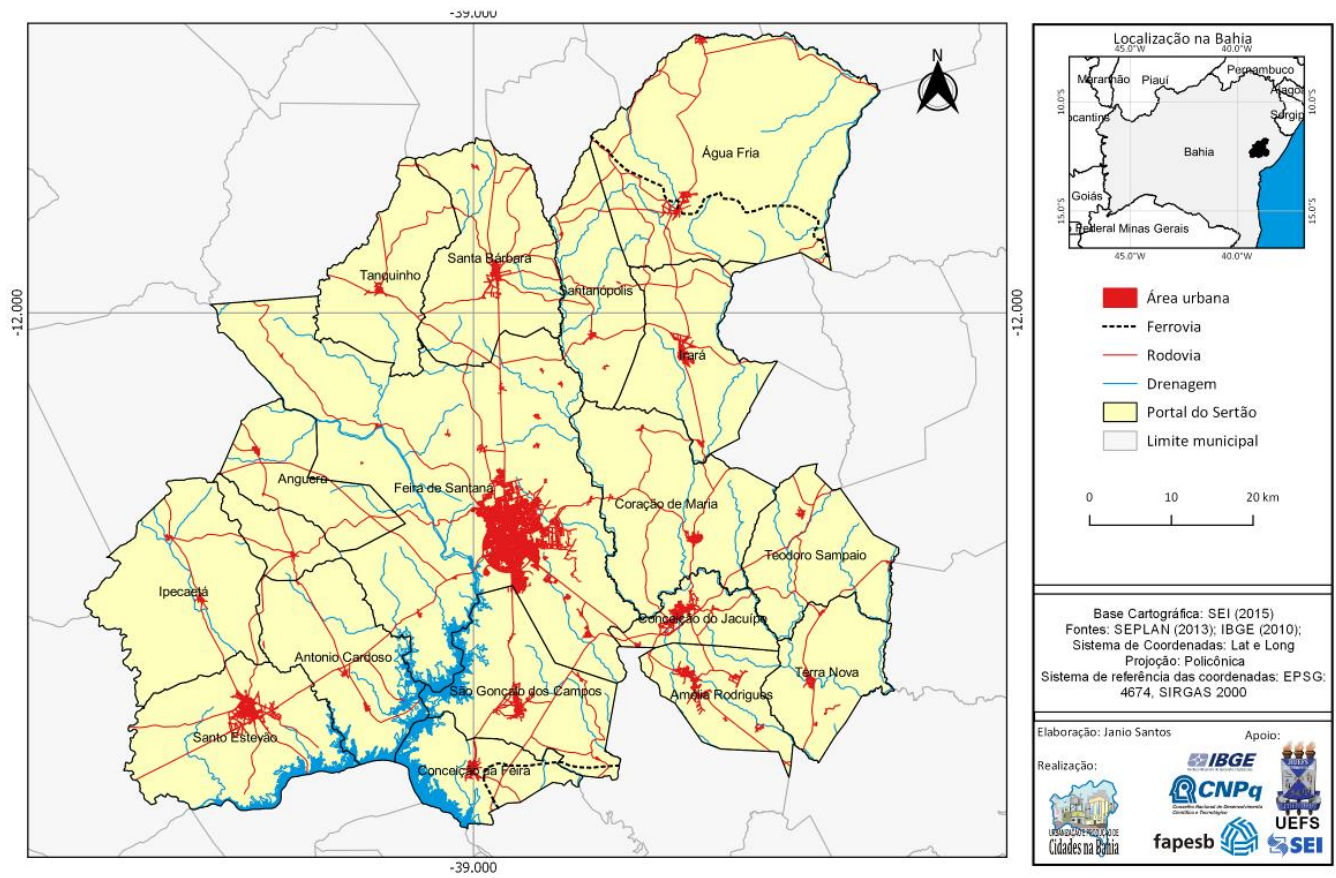

Entre os séculos XVII e XVIII, fora os itens supracitados, também são fundamentais para compreender a ocupação da área: a rota de passagem dos tropeiros, a germinação de feiras livres e as missões jesuíticas, porque tiveram forte influência na instalação de pequenos lugarejos, respectivamente, em função da escolha de locais de descanso das tropas, trocas de produtos e edificação de igrejas.

A grosso modo, a passagem dos tropeiros, as feiras livres, as missões jesuíticas, a criação de gado, os engenhos e uso das águas do Rio Paraguaçu foram as principais dinâmicas que, a depender do lugar, ao se intensificarem, mudaram a configuração territorial da área no século XIX (IBGE, 2019). Isso porque também adquiriram maior complexidade e expressividade, o que incorreu na criação de núcleos urbanos relativamente mais consolidados, e resultou, inclusive, na elevação de alguns à categoria de cidades. 
As mudanças na conjuntura política nacional entre os séculos XIX e início do XX, que influenciaram a transição do Brasil Colônia para o período do Império e desse para a Primeira República, e na própria lógica da sociedade, com a abolição da escravatura e o avanço na luta por direitos civis, tiveram importância para a região. Todavia, não há registros de alterações abruptas na dinâmica econômica e assim as terras do Território de Identidade Portal do Sertão permaneceram até a década de 1940 fortemente voltadas: à criação de gado; as atividades vinculadas à navegação de cabotagem, às margens do Rio Paraguaçu; aos decadentes engenhos de cana de açúcar; e, sobremodo, ao fortalecimento das feiras livres locais ou regionais.

Claro que houve diversificação e ampliação da atividade primária, com visibilidade maior de produtos como fumo, mandioca, feijão e extração da lenha. Outro aspecto foi a construção da Estrada de Ferro Central da Bahia, com conclusão do ramal que ligava a cidade de Cachoeira à Feira de Santana, aberto para o tráfego em 1876, com 45 quilômetros, e do pequeno trecho entre Cruz e São Gonçalo (ZORZO, 1999), aberto ao tráfego em 1886, com 3 quilômetros. Sem esquecer a abertura das primeiras estradas de rodagem, vias que deram origem a BR-116 e a Bahia-Feira de Santana (TEIXEIRA, 1988), que, com a ferrovia, favoreceram a articulação entre os núcleos urbanos maiores e as pequenas aldeias.

No que tange à organização político administrativa, com base nos dados dos primeiros censos realizados no Brasil: em 1872, as terras do Território de Identidade Portal do Sertão eram divididas entre quatro municípios: Santo Amaro, Purificação, Feira de Sant'Anna e Cachoeira. Em 1900, parte de Cachoeira foi desmembrada para formar o município de São Gonçalo dos Campos e as terras de Purificação deram origem a Coração de Maria e Irará. Em 1933, parte de São Gonçalo dos Campos formou "Santo Estevam", divisão territorial essa que perdurou até o censo de 1940, quando a área do Portal do Sertão possuía apenas sete municípios (Figura 2). 
Figura 2- Evolução Político-administrativa do Território de Identidade Portal do Sertão, Bahia, 1872-1970

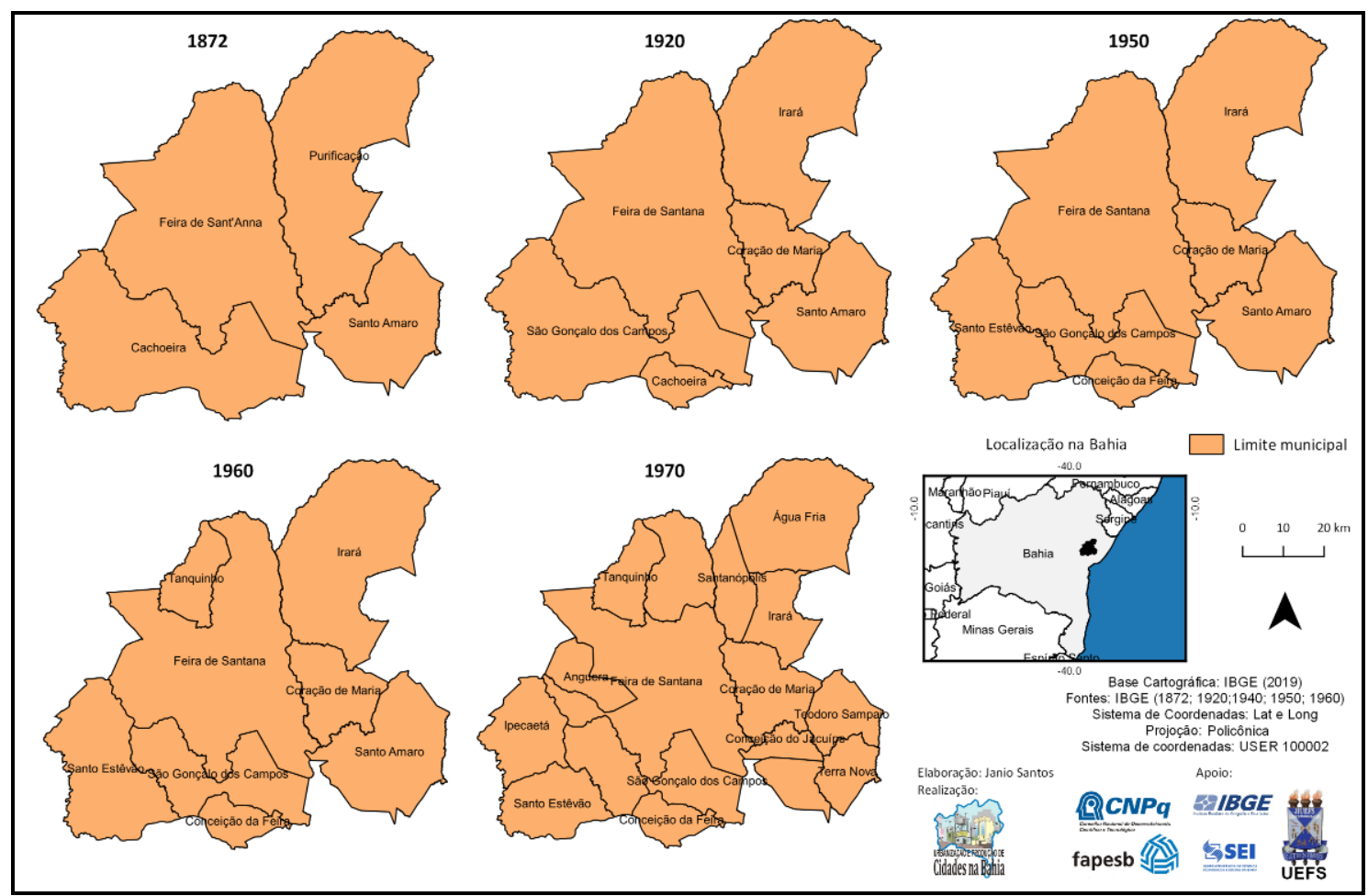

O entendimento de que a urbanização é um movimento histórico, ou seja, um processo, que resulta na produção de áreas urbanas, dentre as quais destacam-se as cidades, permite compreender que as supramencionadas mudanças políticas, sociais e econômicas no Território de Identidade Portal do Sertão tiveram forte influência na conformação de núcleos urbanos, entre o final do século XVI e a década de 1940, período que compreende menos de 400 anos e que, neste texto, é denominado como urbanização pretérita.

Com a colonização, uma nova lógica de povoamento da região ocorreu após o final do século XVI. Todavia, foi a partir de meados do século XVII que os primeiros núcleos surgiram, os quais, posteriormente, germinaram as cidades e vilas do Portal do Sertão. Os registros oficiais iniciais, inclusive, ocorreram em 1696, quando foram criadas a freguesia de Feira de Sant'anna e o distrito de São Gonçalo dos Campos. No século XVIII, especificamente em 1718, foi criado outro distrito, o São João Batista de Água Fria. Todavia, até quase metade do século XIX, 
em termos formais, exceto a criação de algumas freguesias, não houve mudança nessa lógica, que era basicamente administrativa (IBGE, 1958a, 1958b).

A partir da metade do século XIX, a expansão de atividades importantes como a criação de gado, o cultivo da cana de açúcar e o fortalecimento das feiras livres mudaram um pouco a economia do Portal do Sertão, e isso influenciou na dinâmica urbano-regional. Prova disso é que, em 1832, São João Batista de Água Fria foi elevado à categoria de vila, com denominação simplificada para Água Fria $^{3}$, e passou a condição de distrito em 1842; Feira de Sant'anna também elevou-se à categoria de vila, em $1832^{4}$. Após esse contexto, foram criados novos distritos na região: Bom Jardim (Teodoro Sampaio), em 1839; Resgate de Umburanas (Antônio Cardoso), em 1843; Conceição da Feira, em 1847; Santíssimo Coração de Maria (Coração de Maria), Almas (Anguera) e São José de Itapororoca (Maria Quitéria), em 1857; Itacurussá (Bonfim da Feira), Humildes, Remédio da Gameleira (Governador Dr. João Durval Carneiro) e Santa Bárbara, em 1859; Santana do Lustosa (Lustosa), em 1876; Bom Despacho (Jaguara), em 1877; e Tanquinho, em 1879 (IBGE, 1958a, 1958b).

Entretanto, foi apenas no final do século XIX que as primeiras cidades do Portal do Sertão foram formalmente criadas: a Cidade Comercial de Feira de Sant'anna, em 1873, que já possuía a maior dinâmica dentre as demais; Santíssimo Coração de Maria, em 1891; Irará, em 1895, quando houve a mudança da sede de Água Fria; e São Gonçalo dos Campos, em 1897. Todavia, é essencial destacar que, na época, parte das atividades econômicas da região tinha forte relação com o que ocorria em Salvador e Cachoeira, as duas cidades mais importantes do Estado na época, e que, de certa forma, influenciavam a dinâmica urbana do Portal do Sertão (IBGE, 1958a, 1958b).

Entre 1911 e 1937, a criação de 14 distritos na região denota a formação e o fortalecimento de novos núcleos urbanos. Isso ocorreu pari passo à consolidação da área como eixo de articulação entre o Sertão e o Recôncavo Baiano e entre o Nordeste e o Sudeste do Brasil, com destaque para Feira de 
Santana, que exercia papel como importante centralidade, não exclusivamente para o Território de Identidade Portal do Sertão. A construção da ferrovia, a abertura da estrada Bahia-Feira e a construção da BR-116, cuja inauguração do trecho de Feira de Santana ocorreu em 1933, sinalizam para a constituição do formidável entroncamento que germinava.

Para as questões político-administrativas dos municípios no Brasil, os parâmetros adotados pelo Decreto-Lei 311, de 02 de março de 1938, alteraram a lógica pretérita de definição das "áreas urbanas". No Art. $3^{\circ}$, compreendeu-se que "A sede do município tem a categoria de cidade e lhe dá o nome [...]. O distrito se designará pelo nome da respectiva sede, a qual, enquanto não for erigida em cidade, terá, a categoria de vila [...] No mesmo distrito não haverá mais de uma vila". (BRASIL, 1938). Com base nessa norma, passa-se a entender que as cidades brasileiras constituem-se enquanto esferas administrativas; portanto, ser cidade no Brasil afirmou-se, também, como uma condição política.

Quando analisados os dados do Censo Demográfico de 1940, nota-se que, no âmbito da lei, a configuração urbana do Portal do Sertão era composta por apenas seis cidades: Feira de Santana, São Gonçalo dos Campos, Coração de Maria, Irará, Santo Estêvão e Conceição da Feira55; 24 vilas e inúmeros povoados. Independente da precariedade das informações e da validade dos dados, foi a primeira vez na história que a contagem censitária no Brasil passou a ser organizada segundo a situação dos moradores, sistematizada em urbana, suburbana e rural.

\section{INDUSTRIALIZAÇÃO BRASILEIRA E URBANIZAÇÃO NO PORTAL DO SERTÃO}

As mudanças econômicas, políticas e sociais ocorridas a partir de 1940, no Brasil e, em particular, no Estado da Bahia, redundaram em novas lógicas que influenciaram a produção de cidades no Território de Identidade Portal do Sertão. A primeira alteração na organização espacial urbana a ser mencionada é 
que, entre os Censos Demográficos de 1950 e 1970, nos termos do Decreto-lei de 1938, o número de cidades passou de 6 para 17, isso em função da emancipação de 11 antigos distritos, quais sejam: em 1952, Tanquinho; em 1961: Amélia Rodrigues, Anguera, Conceição do Jacuípe, Santa Bárbara, Teodoro Sampaio e Terra Nova; e 1962: Água Fria, Antônio Cardoso, Ipecaetá e Santanópolis IBGE (2019).

Na década de 1950, as descrições feitas pelo IBGE (1958a, 1958b) apontam que as atividades econômicas, na maioria dos municípios, estavam concentradas na agricultura e na pecuária. Nesse setor produtivo, a produção de fumo em folha possuiu destaque como principal produto cultivado na região, seguido pela mandioca. Outros cultivos também apresentavam relevância, como feijão, em Conceição da Feira, Feira de Santana, Santo Estêvão e São Gonçalo dos Campos; abacaxi, em Coração de Maria; milho, em Feira de Santana e Santo Estêvão; e amendoim em casca, em São Gonçalo dos Campos. Ainda podem ser ressaltados produtos menos expressivos, com observação sobre atividades de subsistências em toda região.

A pecuária tinha na criação do gado bovino outra atividade importante para o Portal do Sertão, cujo destaque é dado a Feira de Santana enquanto centro principal de comercialização, onde existiam vários matadouros, e que fornecia produtos para outros municípios da Bahia e do Brasil. Aliás, a cidade já era mencionada como principal entreposto comercial e de ligação entre o Sertão e a capital, Salvador, e entre as regiões Nordeste e Sudeste (IBGE, 1958a, 1958b).

Observa-se a presença de pequenas unidades industriais, claramente incipientes e muito ligadas à produção agrícola ou ao artesanato. Exceto em Feira de Santana, nos demais municípios o destaque é dado à produção de farinha de mandioca. Contudo, também há registros de indústria extrativa para fabrico de lenha em Santo Estêvão e São Gonçalo dos Campos; aguardente, em São Gonçalo dos Campos e Coração de Maria; cerâmica, em Feira de Santana, São Gonçalo dos Campos e Irará, isso dentre outros produtos menos importantes (IBGE, 1958a, 
14 | Urbanização e produção de cidades no/do Território de Identidade Portal do Sertão

1958b). Adverte-se que a presença dessas atividades não implica, necessariamente, em um processo de industrialização, pois, como assinala Sposito (1998), o agregado desse setor não representava, ainda, mudanças amplas na dinâmica econômica dos municípios.

Além dessas seis cidades existentes, a configuração urbana do Território de Identidade Portal do Sertão, em 1950, era composta por 26 vilas e vários pequenos povoados, denominados como "outros aglomerados" pelo IBGE (1958a, 1958b). A área urbana de Feira de Santana era obviamente a maior, com 26.559 habitantes, e apenas mais treze outras cidades menores e vilas possuíam entre 1.000 e 4.000 habitantes. Coração de Maria, já emancipada, tinha somente 812 habitantes.

Dentre os povoados, em poucos havia população superior a 200 habitantes, quais sejam: Limoeiro e São Nicolau, em Feira de Santana, com 250 habitantes cada; Barra e Irapi, em Irará, respectivamente, com 270 e 210 habitantes; e Cruz e Santana, em São Gonçalo dos Campos, respectivamente, com 270 e 200 habitantes. Ainda assim, tais aglomerados eram maiores que algumas vilas, como Ipuaçu (anteriormente denominada Remédio da Gameleira, atual Governador Dr. João Durval Carneiro), em Feira de Santana; Ipecaetá, então pertencente à Santo Estevão; e Itacava, em Coração de Maria, os quais possuíam, respectivamente, com 162, 142 e 132 habitantes (IBGE, 1958a, 1958b).

A dinâmica urbana existente no Portal do Sertão, na década de 1950, pode ser retratada ao ter como base alguns elementos: as articulações econômicas e o fluxo de capital e mercadorias que se engendravam entre os pequenos municípios e Feira de Santana, e entre alguns desses e cidades como Salvador, Cachoeira, Santo Amaro e Alagoinhas; e as atividades agrícolas, inclusive de subsistência, pecuárias, industriais e artesanais, que nutriam a circulação de produtos e pessoas nas feiras livres, cujo principal centro era Feira de Santana. Ademais, os dados populacionais citados sinalizam que, talvez a exceção dessa 
última cidade, a região era composta por áreas urbanas bastante compactas, ou seja, com baixa extensão territorial.

Ainda que existissem rodovias federais e estaduais (precárias) que ligavam as principais cidades do Portal do Sertão, fora os enlaces econômicos, há indícios de baixa interação no âmbito da vida cotidiana entre as áreas urbanas, em especial, os núcleos menores. A limitada presença de artefatos técnicos no território, correspondentes aos meios de comunicação, e dificuldades no acesso a transporte público e mesmo a eletricidade, características da época, avivavam tal fato. Isso revela que outros espectros da vida urbana no Portal do Sertão, na metade do século $X X$, eram influenciados pela construção imaginária feita por viajantes que retornavam as cidades, vilas e povoados, ou, quando disponível, advinda do rádio e dos "alto-falantes". Portanto, eram comuns a parte dos residentes, sobremodo mais pobres, experiências urbanas concretas de vidas (tais como práticas de lazer, consumo etc.), relacionadas, quase que de modo exclusivo, ao imediato.

Deve-se ressaltar que não há ausência integral de conexões com o que ocorre em outros lugares do mundo à época e, certamente, a difusão de informações por rádio era expressiva, com destaque para os serviços de "altofalantes". Mesmo fora de Feira de Santana, que obviamente continha maior infraestrutura e era considerada "cidade moderna", a presença de equipamentos nas pequenas cidades sinaliza conexões com a genuína vida urbana, comprovada pela presença de um jornal impresso em São Gonçalo dos Campos, 10 bibliotecas públicas nas seis cidades e 4 cinemas, dentre os quis cita-se o Vox, em São Gonçalo dos Campos; o São José, em Irará; e o Conceição, em Conceição da Feira (IBGE, 1958a, 1958b).

A partir da metade do século XX, contudo, verifica-se que a urbanização, em função da própria industrialização, mostrava as novas faces do engendramento das forças produtivas do capitalismo no Brasil. As imposições do sistema em 
avançar para alguns "países subdesenvolvidos", no sentido de implantar novas empresas, redefiniram as relações tempo-espaço e refletiram na produção de meios técnicos que articularam a região produtora, no caso, a Região Sudeste, às demais do país, como a Região Nordeste, o que alterou a divisão territorial, técnica e social do trabalho (SANTOS, 1993).

Por isso, no caso específico do Portal do Sertão, a implantação e/ou melhoramento de rodovias federais e estaduais, como a BR-101 e a BR-324, enquanto produtos dessa nova dinâmica econômica, mudou as relações tecidas no âmbito das áreas urbanas. Por um lado, fez eclodir novos núcleos e aglomerados em regiões mais estratégicas para o rodoviarismo, alguns próximos às suas margens, e declinar outros, até então mais consolidados. Essa dinâmica fortaleceu ainda mais o papel de cidades cujo porte era relativamente maior, como é o caso de Feira de Santana.

A política de articulação do território brasileiro fez com que houvesse maior fluidez nas relações entre os espaços, que decorreu em maior circulação de mercadorias, capital e, sobretudo, trabalhadores. No Portal do Sertão verifica-se que a mobilidade do trabalho, sobretudo, entre campo e cidade, foi notória e não restrita aos deslocamentos para os grandes centros urbanos brasileiros, ainda que a Região Sudeste fosse o principal foco. Considera-se isso porque é fundamental observar que parte da população de área rural dessa região também migrou para a Região Metropolitana de Salvador (RMS) e para a cidade de Feira de Santana, sobretudo a partir da década de 1960.

Milhares de camponeses migraram na Bahia, acima de tudo, porque foram expropriados de suas terras, em função de três processos apontados por Santos (2010): a ausência de políticas que garantissem a permanência do homem no campo; a mecanização/modernização da agricultura; e face períodos de crise na atividade agrícola. Por outro lado, isso criou possibilidades para expansão de vários povoados e vilas, mas, sobretudo, de médias e grandes cidades, pois, 
enquanto locais de decisões e comando, essas últimas criavam as condições materiais e subjetivas para sustentar e reproduzir a lógica urbano-industrial vigente. Inclusive, que reforçou o pseudo-ideal da cidade como "quimera" única da melhoria da qualidade de vida, trazido da própria modernidade.

Também por isso que, com base nos dados dos censos demográficos do IBGE, a partir das décadas de 1940 e 1950, a tendência mais comum no Portal do Sertão, como em vários outros municípios do Brasil, foi a perda ou o crescimento geométrico anual relativamente menor da população rural, em relação à população urbana, que tendeu a crescer em taxas mais altas (Tabelas 1 e 2). Afirma-se isso, ainda que os dados sejam pouco confiáveis nessa época. Como nesse contexto ocorreram vários desmembramentos, oscilações abruptas nos dados urbanos e rurais ocorreram e precisam ser cuidadosamente analisadas.

O êxodo rural aponta, nomeadamente, a falta de políticas de permanência no campo por parte dos governos, que, invés de auxiliar o pequeno produtor a qualificar sua vida na zona rural, criou políticas que os expulsaram do lugar de origem e Ihes tiraram as condições concretas, a posse da terra, impelindo-os a se tornarem mão de obra assalariada. Isso alinha-se, por outro lado, a uma sociedade que incutia no imaginário coletivo ideais da cidade, e em particular da indústria, como possibilidades únicas para o desenvolvimento.

Entretanto, foi a partir da década de 1970, sobremodo com a criação do Centro Industrial do Subaé (CIS), instalado em Feira de Santana, que a atividade industrial ganhou nova dinâmica no Portal do Sertão, isso dentro da proposta do governo estadual em implantar unidades industriais fora da RMS, com estímulo para criação de distritos vinculados ao setor secundário em outras cidades da Bahia. Como aponta Freitas (2009), sua implantação refletiu o discurso cepalino ${ }^{6}$ de superar o "atraso" da América Latina, o que interiorizou a implantação dos centros industriais baianos e materializou demandas das elites locais. 
18 | Urbanização e produção de cidades no/do Território de Identidade Portal do Sertão

Tabela 1- Taxa de Crescimento Geométrico anual da População da cidade¹, por sede municipal - Território de Identidade Portal do Sertão - 1940-2010

\begin{tabular}{|c|c|c|c|c|c|c|c|}
\hline Municípios & $\begin{array}{l}2000- \\
2010\end{array}$ & $\begin{array}{l}1991- \\
2000\end{array}$ & $\begin{array}{l}1980- \\
1991\end{array}$ & $\begin{array}{l}1970- \\
1980\end{array}$ & $\begin{array}{l}1960- \\
1970\end{array}$ & $\begin{array}{l}1950- \\
1960\end{array}$ & $\begin{array}{l}1940- \\
1950\end{array}$ \\
\hline Água Fria & 4,06 & 6,06 & 6,77 & 3,62 & 4,93 & 0,22 & $-2,52$ \\
\hline Amélia Rodrigues & 0,93 & 1,84 & 3,85 & 5,99 & 3,32 & 5,06 & 4,24 \\
\hline Anguera & 2,27 & 1,65 & 1,97 & 3,72 & $-0,51$ & 4,75 & 2,85 \\
\hline Antonio Cardoso & 2,45 & 3,70 & 1,45 & 1,58 & $-4,91$ & 0,90 & \\
\hline $\begin{array}{c}\text { Conceição da } \\
\text { Feira }\end{array}$ & 1,57 & 3,80 & 1,94 & 4,27 & 3,42 & 3,17 & 0,73 \\
\hline $\begin{array}{c}\text { Conceição do } \\
\text { Jacuípe }\end{array}$ & 1,92 & 2,08 & 3,53 & 4,50 & 8,73 & & \\
\hline Coração de Maria & 2,01 & 3,11 & 2,20 & 4,70 & 6,61 & 5,61 & 1,45 \\
\hline Feira de Santana & 1,68 & 2,35 & 3,76 & 5,98 & 7,50 & 5,80 & 9,51 \\
\hline Ipecaetá & 2,71 & 5,04 & 3,48 & 2,47 & 4,47 & 5,73 & 4,67 \\
\hline Irará & 2,61 & 1,89 & 4,13 & 5,02 & 1,47 & 4,20 & 0,32 \\
\hline Santa Bárbara & 2,22 & 4,30 & 5,24 & 3,74 & $-0,68$ & 3,75 & 2,42 \\
\hline Santanópolis & 3,68 & 6,59 & 0,63 & 5,99 & $-1,13$ & $-0,19$ & 5,43 \\
\hline Santo Estevão & 3,47 & 5,04 & 4,99 & 5,04 & 4,00 & 7,85 & 3,25 \\
\hline $\begin{array}{c}\text { São Gonçalo dos } \\
\text { Campos }\end{array}$ & 1,86 & 2,23 & 4,02 & 0,96 & 1,14 & $-4,23$ & 10,20 \\
\hline Tanquinho & 0,73 & $-1,01$ & 2,20 & 5,09 & 2,93 & 2,94 & 3,83 \\
\hline Teodoro Sampaio & $-0,82$ & $-0,08$ & 1,14 & 0,93 & 3,52 & 3,66 & 2,95 \\
\hline Terra Nova & 0,24 & 1,18 & 1,80 & 2,38 & 1,36 & & \\
\hline Portal do Sertão & 1,74 & 2,41 & 3,65 & 5,42 & 6,00 & 5,25 & 7,36 \\
\hline
\end{tabular}

Fonte: IBGE $(1940 ; 1950 ; 1960 ; 1970 ; 1980 ; 1991 ; 2000 ; 2010)$

Organização do autor

Nota: 1 - Em cinza, dados referentes à população da sede do distrito, antes da emancipação. 
Tabela 2- Taxa de Crescimento Geométrico anual da População da rural, por municípios Território de Identidade Portal do Sertão - 1970-2010

\begin{tabular}{ccccc}
\hline Municípios & $\mathbf{2 0 0 0 - 2 0 1 0}$ & $\mathbf{1 9 9 1 - 2 0 0 0}$ & $\mathbf{1 9 8 0 - 1 9 9 1}$ & $\mathbf{1 9 7 0 - 1 9 8 0}$ \\
Água Fria & $-0,43$ & $-0,65$ & $-0,16$ & 1,13 \\
Amélia Rodrigues & 0,23 & $-2,36$ & $-0,30$ & $-1,73$ \\
Anguera & 0,96 & 1,09 & $-0,84$ & $-0,45$ \\
Antonio Cardoso & $-1,10$ & $-1,36$ & $-0,25$ & $-0,77$ \\
Conceição da Feira & 1,46 & $-2,70$ & 0,15 & $-0,38$ \\
Conceição do Jacuípe & $-0,22$ & 0,00 & $-1,17$ & $-0,51$ \\
Coração de Maria & $-2,23$ & $-0,05$ & $-0,09$ & 0,30 \\
Feira de Santana & $-0,67$ & $-1,60$ & $-0,16$ & 0,41 \\
Ipecaetá & $-2,48$ & 0,97 & $-0,54$ & $-0,35$ \\
Irará & $-0,17$ & 0,00 & 0,44 & 1,46 \\
Santa Bárbara & $-0,35$ & $-1,20$ & $-0,34$ & $-0,34$ \\
Santanópolis & $-0,42$ & $-1,59$ & $-0,59$ & $-0,91$ \\
Santo Estevão & $-0,60$ & $-1,40$ & 0,33 & 1,23 \\
São Gonçalo dos & 2,24 & 0,45 & $-0,89$ & $-0,64$ \\
Campos & $-0,35$ & $-6,75$ & $-1,44$ & 1,43 \\
Tanquinho & $-3,66$ & $-3,50$ & $-2,20$ & $-2,68$ \\
Teodoro Sampaio & $-2,78$ & $-2,72$ & $-5,24$ & $-1,41$ \\
Terra Nova & $-0,52$ & $-0,99$ & $-0,33$ & 0,08 \\
Portal do Sertão & & & &
\end{tabular}

Fonte: IBGE (1970;1980;1991;2000; 2010)

Organização do autor

Outro fator importante para entender a dinâmica da urbanização no Portal do Sertão, a partir das décadas de 1960 e 1970, foi o processo de terciarização, ou seja, o predomínio e o fortalecimento de atividades vinculadas ao terciário em relação a outros setores da economia de uma dada área. Por sinal, a intensificação da atividade industrial na região consolidou ainda mais o terciário, com realce para a cidade de Feira de Santana. Dentro desse amplo ramo de atividades, destacam-se para a economia urbano-regional: a ampliação de esferas dos setores públicos, sobretudo, saúde, educação e segurança; a cadeia 
produtiva ligada à construção civil; e as dinâmicas beneficiadas pelas feiras livres, mesmo que, em vários casos, basicamente locais. O setor primário, contudo, permaneceu com importância na maioria dos pequenos municípios, tanto no que diz respeito ao agregado do PIB, quanto no quadro da ocupação de trabalhadores.

Na década de 1970, o Território de Identidade Portal do Sertão já possuía a quantidade de cidades existentes hoje, visto que, após 1962, não houve a promulgação de leis para aprovar pedidos de emancipação, ainda que representantes políticos de alguns distritos o tenham feitos. As principais alterações que ocorreram entre 1970 e 2000 na dinâmica urbana relacionam-se: ao crescimento no número de povoados e vilas, essas últimas em função da criação de novos distritos; a expansão territorial da maioria das áreas urbanas, sobretudo cidades médias e pequenas; e a intensificação de elementos da vida urbana no cotidiano das pessoas, mesmo aquelas residentes no campo, em concomitância com a imposição de determinantes da urbanização sobre o território.

No quadro dos povoados, não há dados disponíveis para 1970, contudo, em 1980, foi registrado um total de 13, com destaques para Picado, em Conceição do Jacuípe, que possuía 1.336 habitantes; e Jaíba, em Feira de Santana, com 955 habitantes. Em 2000, esse número aumentou para 24, com destaques para Bessa e Picado, em Conceição do Jacuípe, que possuíam, respectivamente, 1.199 e 1.184 habitantes (SEI, 2019a).

O quadro de vilas do Portal do Sertão passou de 19, em 1970, para 23, em 2000. Observa-se que, em relação a 1950, houve redução nos números, já que muitas das anteriores vilas foram emancipadas e a criação de novos distritos não correspondeu ao mesmo número. Em 1970, cinco sedes distritais possuíam entre 1.000 e 2000 habitantes, quais sejam: Inhatá e Mata Aliança, em Amélia Rodrigues; Humildes e Bonfim da Feira, em Feira de Santana; e Lustosa, em Teodoro Sampaio. Em 2000, o número de sedes distritais com mais de 1.000 
habitantes passou para 8 e os dados da população residente em tais vilas indicam a expressiva expansão urbana, sobremodo nos casos de Humildes, em Feira de Santana, com 5.660 habitantes; e Inhatá, em Amélia Rodrigues, 3.052 (IBGE, 1970, 2000).

Ao passo que se verifica redução da população rural, o crescimento geométrico anual da população urbana é notável, conforme tabelas 1 e 2. Em 1970, Feira de Santana já era uma cidade "centenária", com 126.972, segunda maior da Bahia (IBGE, 1970). Entre 1970 a 2000, a maioria dos munícipios da RMFS perdeu população rural, principalmente entre 1970 e 1990, quando foram registradas altas reduções, com destaques para Teodoro Sampaio e Terra Nova, com perdas superiores a $-2,0 \%$ ao ano. Em relação à população da cidade, observa-se que a maioria dos municípios apresentava percentuais positivos, alguns com taxas anuais superiores a 5,0\%, a exemplo de Água Fria, Feira de Santana, Ipecaetá, Santa Bárbara, Santanópolis, Santo Estevão e Tanquinho. Concomitantemente, as taxas de urbanização também tornaram-se crescentes a partir dessa época.

O Território de Identidade Portal do Sertão chegou ao século XXI com uma organização territorial urbana marcada por: uma importante cidade média, Feira de Santana, polo regional, com 419.816 habitantes; uma rede de pequenas cidades, algumas com centralidade microrregional, como Santo Estevão e Irará, respectivamente, com 19.693 e 8.289 habitantes; e um quadro representativo de vilas e povoados, que apresentam assaz heterogeneidade e complexidade, com papeis que se definem e transitam entre dinâmicas urbanas claramente consolidadas, como as verificadas em Humildes e Inhatá, e outros bastante incipientes para serem considerados "urbanos", como as vilas de Poço, em Antônio Cardoso, e Itacava, em Coração de Maria, respectivamente, com 219 e 200 habitantes. Também merecem menção os povoados de Itapetingui, na sede de Amélia Rodrigues, e Sete Portas, no distrito de Maria Quitéria, em Feira de Santana, respectivamente, com 83 e 88 habitantes (IBGE, 2000). 


\section{URBANIZAÇÃO NO PORTAL DO SERTÃO: UM QUADRO ATUAL}

Se, entre 1950 e 1980, houve intensos processos de migração, sobretudo das áreas rurais, para a Região Sudeste e para a RMS, nas últimas décadas isso não é mais tão prevalente. Concomitantemente ao deslocamento de pessoas do campo para a cidade, há movimentos de retorno, as vezes sazonais, pois, como as condições de vida tornam-se mais agudas, face à própria crise estrutural do capitalismo, muitos não conseguem trabalhos permanentes e se enredam no que Moreira e Santos (2018) denominam plasticidade do trabalho. Ou seja, sujeitos que conformam suas vidas em ciclos de deslocamentos para lugares diversos e, nessa lógica, exercem variados tipos de trabalhos em caráter temporário, part time, ora na construção civil, ora na agricultura, ora no setor terciário, quase sempre precários e com baixa remuneração

Nas últimas três décadas no Portal do Sertão, por um lado, esse fenômeno envolveu deslocamentos permanentes, pendulares e/ou ocasionais para Feira de Santana, tanto do campo quando de outras cidades pequenas, enredados ainda na ideal da busca por melhores oportunidades de trabalho, nem sempre concretizadas; acesso a serviços mais especializados de saúde e educação; e/ou porque as condições de existência no campo se tornaram desfavoráveis. Há também o fato de muitos migrarem do campo em direção às pequenas cidades: em busca do acesso a serviços, como saúde, educação etc. para a família e filhos, ainda que, em determinadas situações, mantenham as pequenas propriedades rurais; para fugir de condições precárias, face à ausência de políticas sólidas para permanência na zona rural; e/ou pela oferta de residências em programas habitacionais nessas cidades.

Sobre os aspectos econômicos, o Portal do Sertão possuía, em 2016, um PIB total de $18.688 .638,00$, que correspondiam a $7,23 \%$ em relação ao total do Estado. Isso demonstra variação com tendência a maior dinamismo da região como um todo, se comparado com 2002, quando o total do PIB era de 2.833.780 
e correspondia a 4,82\% em relação à Bahia. No âmbito regional, merecem destaques Conceição da Feira, São Gonçalo dos Campos e, sobretudo, Conceição do Jacuípe, que apresentaram crescimento da participação na Bahia e, sobretudo, na região em análise (Tabela 3).

Feira de Santana mantem-se com a terceira maior economia da Bahia e concentrava mais de $70 \%$ da riqueza produzida no Portal do Sertão. Sua participação no estado passou de 4,82\%, em 2002, para 7,23\%, em 2016. Todavia, os dados assinalam que houve redução na participação de Feira de Santana na região, o que não é um paradoxo. Apenas indica que, pari passo, teve maior dinamismo em outros municípios e isso, relativamente, reduziu a participação dessa cidade no contexto regional. São Gonçalo dos Campos e Conceição do Jacuípe são os dois casos mais expressivos, pois passaram, respectivamente, de 1,98\% e 5,42\%, em 2002, para 4,12\% e 10,83\%, em 2016. Que esses dados não iludam os pesquisadores, pois, fora do eixo dos municípios diretamente envolvidos na dinâmica de Feira de Santana, a tendência principal foi de redução nas esferas regional e estadual.

No Portal do Sertão, as maiores contribuições dos PIB's municipais, em 2016, advinham do setor terciário e, em segundo, do industrial, algo que não é recente. Os dados revelam tendências que ocorrem desde final da década de 1980, quando as atividades primárias e secundárias deixaram de ser as principais composições dos PIB's em quase todos os municípios, com exceção de Conceição do Jacuípe, que possuía 55,28\% no setor secundário, em 2016. Entretanto, se analisada apenas sob um prisma apenas, pode haver distorção, já que em vários pequenos municípios os percentuais altos do PIB terciário têm relação direta com despesas vinculadas aos serviços públicos, o que torna evidente a pseudoterciarização, ou seja, um setor comercial e de serviços que se suprimido o papel do Estado é pouco dinâmico (Figura 3).

Outros dados revelam os limites em analisar as economias municipais exclusivamente com base no PIB, e a ocupação, ou seja, os setores que, 
24 | Urbanização e produção de cidades no/do Território de Identidade Portal do Sertão

formalmente, empregam a população, é um bom exemplo. Ainda que seja evidente a terciarização e, simultaneamente, tenha havido redução nos percentuais a partir da década de 1990, fica assaz claro que em vários municípios parte representativa da População Econômica Ativa (PEA), em 2010, estava ocupada no setor primário. Em 12 desses os valores eram superiores à $32 \%$ e em 7 correspondiam a mais de 50\%; ou seja, mostra que a região ainda reserva importância na atividade agrícola, que a economia é bastante diversificada e que não se pode generalizar a realidade de Feira de Santana, Conceição do Jacuípe e São Gonçalo dos Campos para os demais municípios. Assim, mesmo que a urbanização como tendência seja um fato, esse processo é dialético, contraditório, e ocorre entrelaçado às atividades vinculadas ao campo, mormente, nos pequenos municípios

(Figura

4). 
Tabela 3 - Produto Interno Bruto Total (PIB) ${ }^{1}$, Percentual sobre o total do estado e sobre o total da região, e crescimento em relação ao estado e a região, por municípios - Território de Identidade Portal do Sertão - 2002, 2009 e 2016

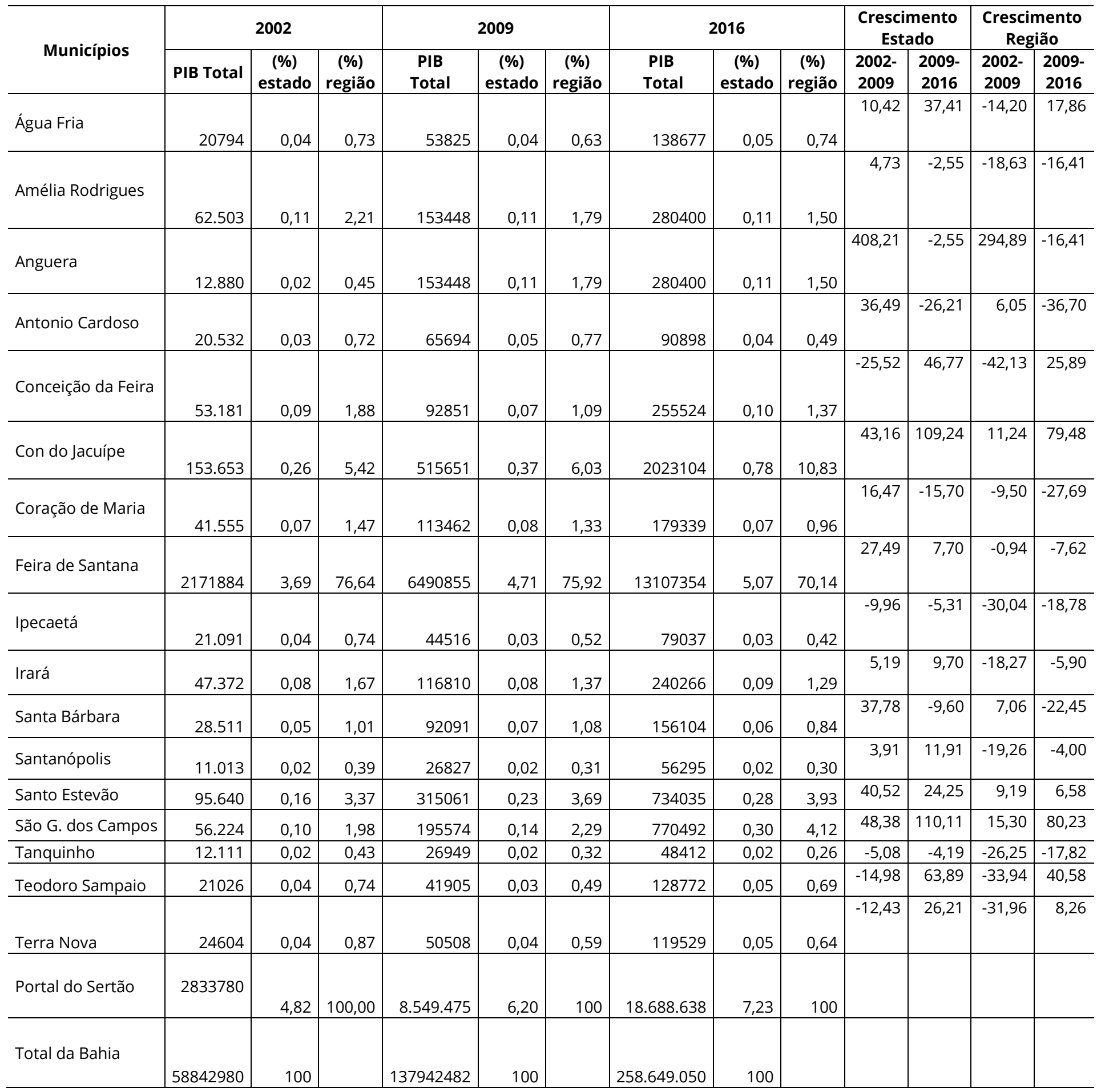

Fonte: IBGE $(2002,2009,2016)$ 
Figura 3- Percentual da participação do Terciário e dos Serviços públicos no Produto Interno Bruto (PIB), Território de Identidade Portal do Sertão, Bahia, 2016

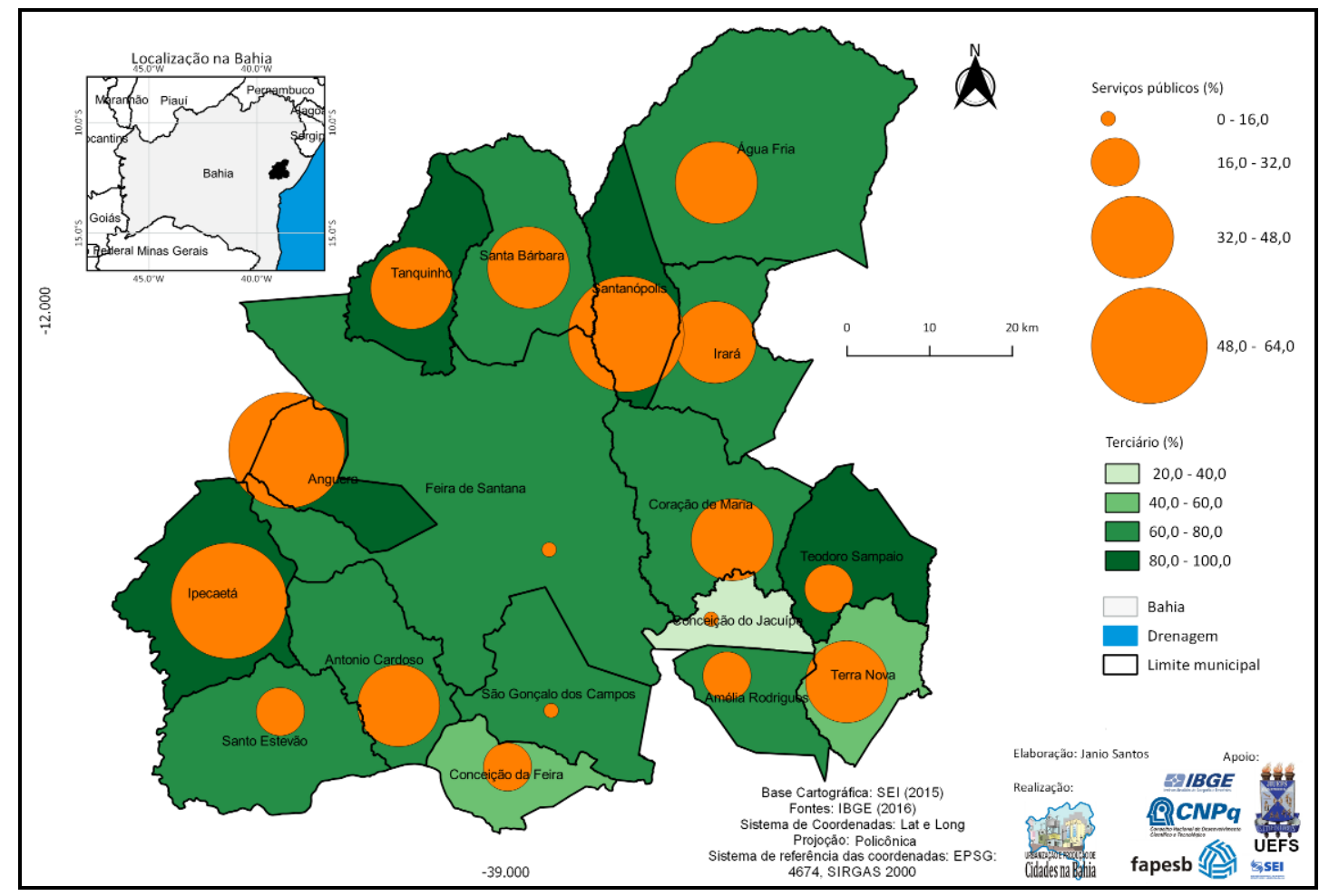

Figura 4- Percentual da população ocupada no setor primário, Território de Identidade Portal do Sertão, Bahia, 2010

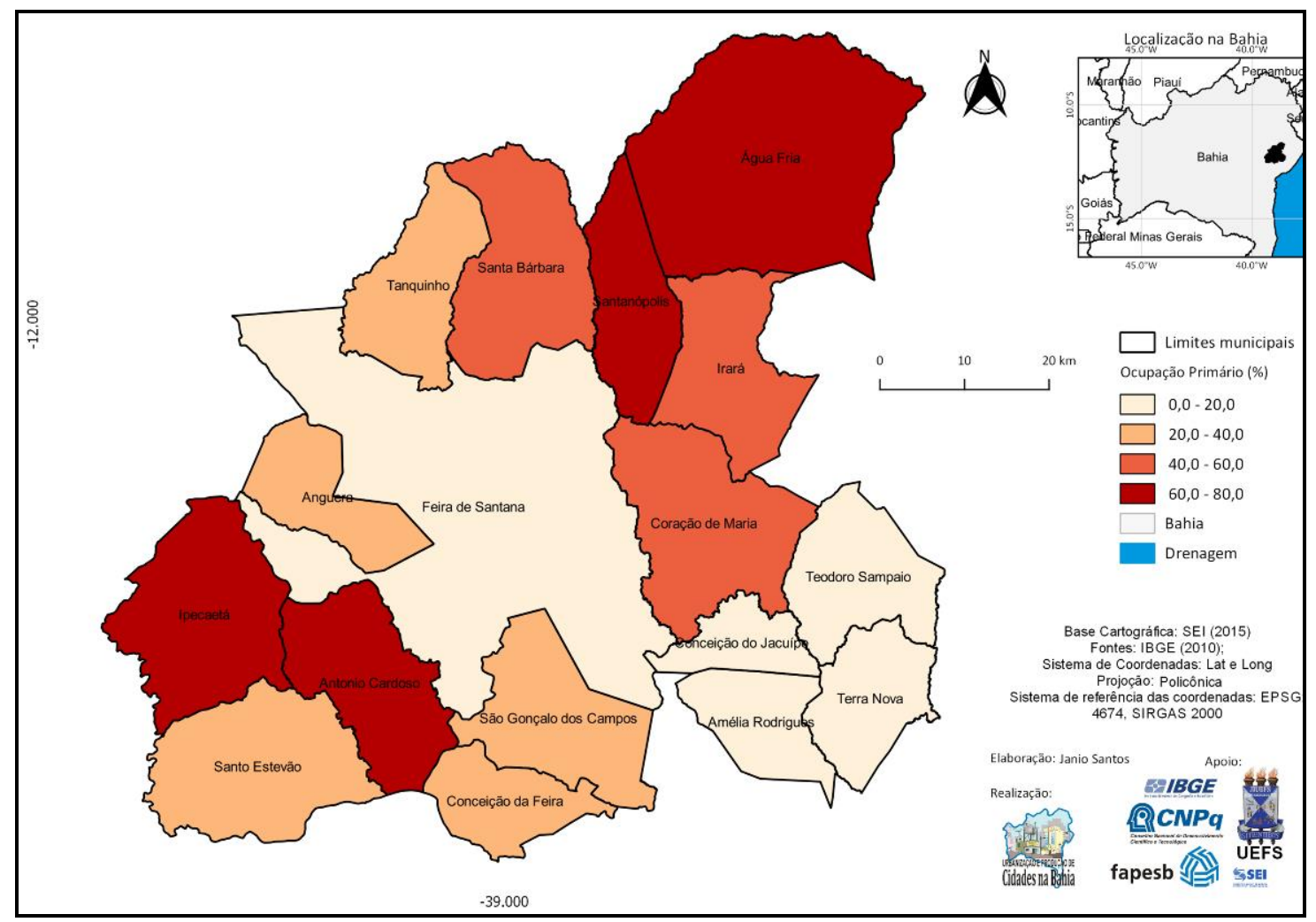


Indiscutivelmente, a atividade industrial do Portal do Sertão está fortemente concentrada em Feira de Santana. Para se ter exemplo, segundo informações da Federação da Indústrias do Estado da Bahia (FIEB, 2019), dos 966 estabelecimentos registrados, 818 estão localizados em Feira de Santana, 41 em Conceição do Jacuípe e 31 em São Gonçalo dos Campos. Dentre os demais, Amélia Rodrigues, Conceição da Feira, Santo Estevão e Coração de Maria possuem, em média, 10 empresas cada.

Na contramão do que apontam os discursos, o setor primário tem importância para a dinâmica econômica do Território de Identidade Portal do Sertão. Inclusive, Feira de Santana, que é sempre destacada pelas atividades industrial e terciária, aparece em realce na produção de alguns itens característicos. Portanto, entender sua urbanização é compreender, também, as relações que são tecidas entre cidades e campo. Feira de Santana foi tida, em 2016, como a maior produtora de codorna e seus derivados, atividade que também tem relevo em Conceição da Feira, Coração de Maria, Conceição do Jacuípe, São Gonçalo dos Campos e Santo Estêvão. O fumo é outro produto vinculado ao setor em Ipecaetá, Antônio Cardoso, Santo Estêvão e Feira de Santana. A criação de galinhas e a produção de seus derivados são relevantes em Conceição do Jacuípe, Feira de Santana, Água Fria, Conceição da Feira, Irará e São Gonçalo dos Camposvii.

No que diz respeito ao terciário do Portal do Sertão, um fato é inconteste: Feira de Santana é a cidade que se apresenta como o grande centro fornecedor de bens e serviços para ampla hinterlândia, relativos aos setores comercial, educacional, saúde, lazer etc., além de ser sede de diversas unidades administrativas do Estado da Bahia, com grau relativamente alto de assistências especializadas. Tais elementos tornam-se favoráveis à promoção de fluxos, pendulares e/ou sazonais, dessa e/ou para essa cidade, sobretudo, para trabalhar, estudar e suprir demandas cotidianas para os residentes na região ou para os que estão de passagem.

Nas demais cidades, o grau de especialização do setor terciário é baixo e, em geral, vincula-se ao atendimento de demandas cotidianas imediatas; aliás, isso ocorre, também, pela própria proximidade com o polo regional. Em Conceição do Jacuípe, São Gonçalo dos Campos, Amélia Rodrigues, Conceição da 
Feira, Santo Estevão e Irará, pela centralidade local ou pela presença da atividade industrial ou de empresas agrícolas, foram instalados equipamentos públicos e privados importantes, sobretudo, ligados aos "serviços produtivos" ou às unidades administrativas do Estado, o que dinamiza o setor localmente.

Disso exposto, no contexto atual, o Território de Identidade Portal do Sertão apresenta-se com uma organização territorial urbana não tão diferente daquela que adentrou o século XXI. Com 495.965 habitantes, segundo o Censo (IBGE, 2010), Feira de Santana é o principal centro da região e capitaneia ampla hinterlândia, composta por várias cidades pequenas, vilas e outros núcleos nãourbanos. Santo Estêvão, Conceição do Jacuípe, Amélia Rodrigues e São Gonçalo dos Campos, respectivamente, com 27.690, 23.539, 16.261 e 15.034 habitantes, são as mais dinâmicas e não é mera coincidência o fato de que três dessas estão fortemente integradas aos processos econômicos que ocorreram em Feira de Santana nas duas últimas décadas (Tabela 4 e Figura 5).

Tabela 4- População Total, Urbana, Rural, da Cidade e Taxa de Urbanização, por municípios - Território de Identidade Portal do Sertão, 2010

\begin{tabular}{lrrrrr}
\hline Municípios & \multicolumn{1}{c}{ Total } & Urbana & \multicolumn{1}{c}{ Rural } & $\begin{array}{c}\text { Taxa de } \\
\text { Urbanização }\end{array}$ & Cidade \\
Água Fria & 15.731 & 5.777 & 9.954 & 36,72 & 4349 \\
Amélia Rodrigues & 25.190 & 19.957 & 5.233 & 79,23 & 16261 \\
Anguera & 10.242 & 4.326 & 5.916 & 42,24 & 4.326 \\
Antônio Cardoso & 11.554 & 3.225 & 8.329 & 27,91 & 1.428 \\
Conceição da Feira & 20.391 & 13.137 & 7.254 & 64,43 & 13.137 \\
Conceição do Jacuípe & 30.123 & 23.539 & 6.584 & 78,14 & 23.539 \\
Coração de Maria & 22.401 & 9.400 & 13.001 & 41,96 & 8.599 \\
Feira de Santana & 556.642 & 510.635 & 46.007 & 91,73 & 495.965 \\
Ipecaetá & 15.331 & 2.637 & 12.694 & 17,20 & 1.452 \\
Irará & 27.466 & 11.246 & 16.220 & 40,95 & 10.724 \\
Santa Bárbara & 19.064 & 8.669 & 10.395 & 45,47 & 8.669 \\
Santanópolis & 8.776 & 1.684 & 7.092 & 19,19 & 1.343 \\
Santo Estevão & 47.880 & 27.690 & 20.190 & 57,83 & 27.690 \\
S. Gonçalo dos Campos & 33.283 & 16.505 & 16.778 & 49,59 & 15.034 \\
Tanquinho & 8.008 & 5.711 & 2.297 & 71,32 & 5.711 \\
Teodoro Sampaio & 7.895 & 6.341 & 1.554 & 80,32 & 3.848 \\
Terra Nova & 12.803 & 11.488 & 1.315 & 89,73 & 9.651 \\
Total & $\mathbf{8 7 2 . 7 8 0}$ & $\mathbf{6 8 1 . 9 6 7}$ & $\mathbf{1 9 0 . 8 1 3}$ & $\mathbf{7 8 , 1 4}$ & $\mathbf{6 5 1 7 2 6}$ \\
\hline
\end{tabular}

Fontes: IBGE (2010) 
Figura 5- População das Cidades, Vilas e Povoados do Território de Identidade Portal do Sertão, Bahia, 2010

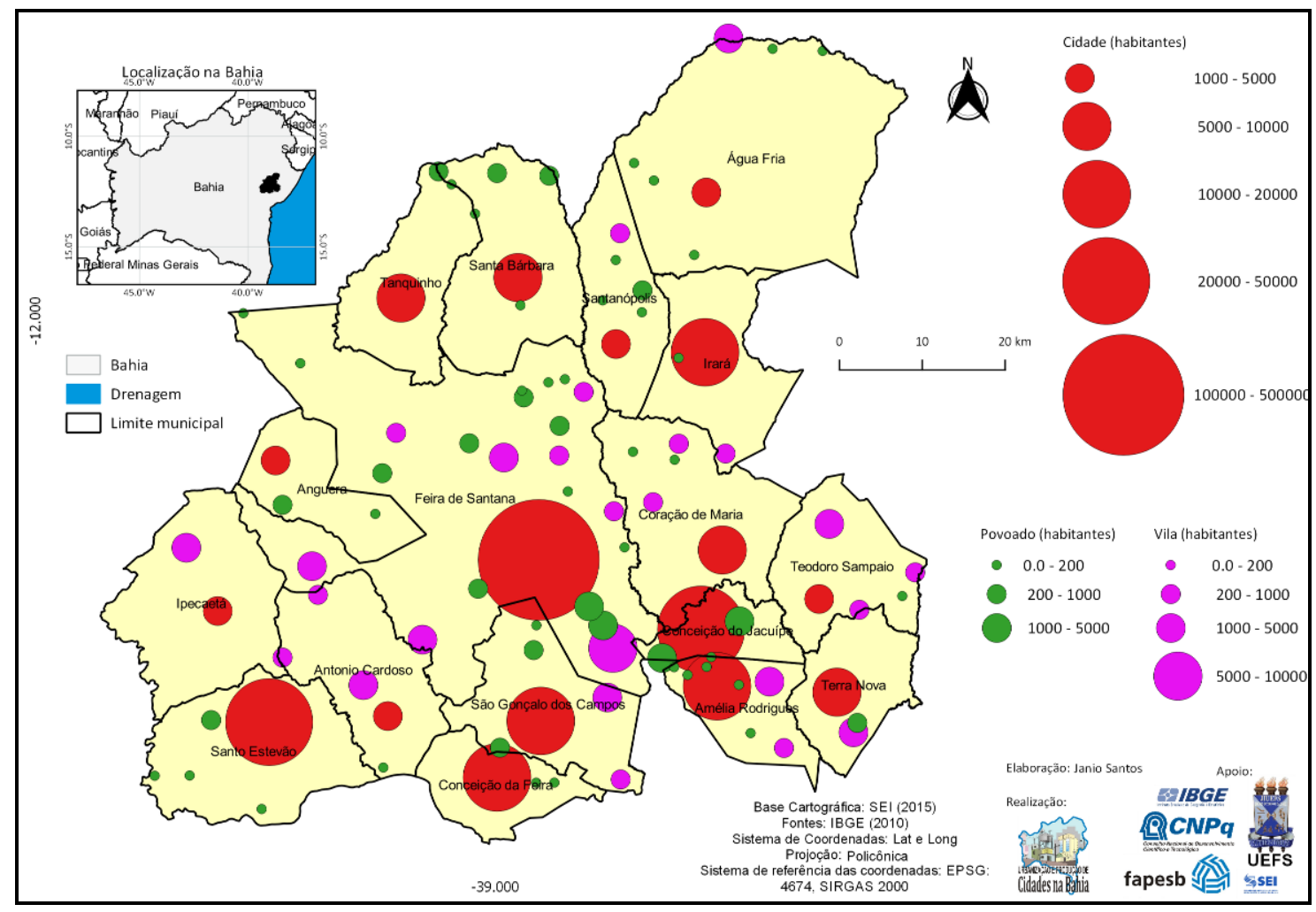

Em 2010, existiam 25 vilas constituídas por lei no Portal do Sertão, aumento de apenas duas em comparação a 2000. A relação com Feira de Santana e, mormente, a presença da atividade industrial fortaleceram ainda mais a característica de Humildes como o principal núcleo urbano dessa categoria, a qual possuía 6.983 habitantes e era maior do que 7 cidades da região. Nesse mesmo ano, mais 10 vilas tinham entre 1.000 e 3.000 habitantes; todavia, das 25 existentes, três não possuíam mais do que 300 habitantes e são menores do que muitos aglomerados considerados "não-urbanos" pelo IBGE (Figura 6).

O quadro dos povoados revela confusão em relação às informações encontradas no IBGE, imprecisões que prejudicam leituras mais concisas da realidade concreta. Há vários aglomerados rurais existentes que não são considerados pelo órgão, como Paiaiá, em Santo Estêvão, e Quilombo, em Santanópolis; e outros, os quais não apresentam formação de núcleos, e são registrados pelo órgão. Portanto, com base em metodologia desenvolvida pelo 
Grupo de Pesquisa, foram encontradas 54 áreas que podem ser consideradas “povoados" no Portal do Sertão. Os destaques são Picado e Bessa, em Conceição do Jacuípe, que possuíam, respectivamente, 1.382 e 1.262 habitantes; Magalhães, em São Gonçalo dos Campos, com 654 habitantes; e Alecrim Miúdo, em Feira de Santana, com 542 habitantes (IBGE, 2010), todos maiores que muitas vilas, consideradas “urbanas” pelo IBGE.

Figura 6- Cidades, Vilas e Povoados do Território de Identidade Portal do Sertão, Bahia, 2019
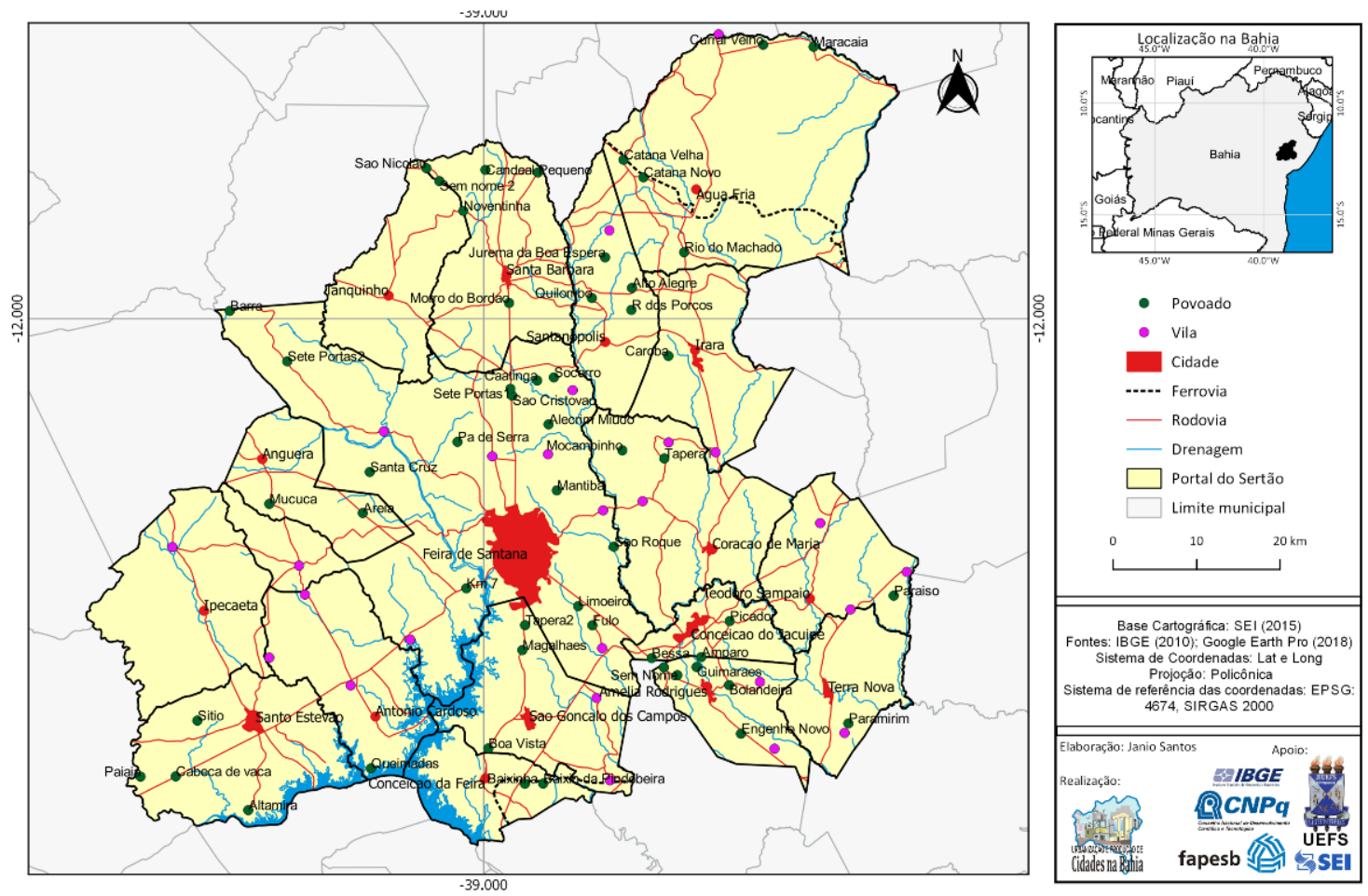

Nos eixos entre Feira de Santana, Conceição do Jacuípe e São Gonçalo dos Campos verifica-se que determinadas áreas, avaliadas como "aglomerados rurais" no Censo de 2010, passaram por forte expansão, sobretudo face interesses imobiliários e especulativos, e, claramente, adquiriram dinâmicas urbanas bastante consolidadas. Isso tende a diluir os traços rurais de antigos aglomerados e conforma possibilidades de futuras de conurbações, algo mais 
evidente entre Feira de Santana, São Gonçalo dos Campos e Conceição do Jacuípe, conforme Figuras 1 e 5.

Por outro, tornam-se mais conflituosas as questões sobre limites intermunicipais, como as existentes entre Feira de Santana e São Gonçalo dos Campos, que vieram à tona após o Governo do Estado promulgar a Lei 12.057 que visa solucionar litígios territoriais entre municípios. Após um convênio celebrado entre a SEI e o IBGE, foram adotadas metodologias para consolidar a divisão político-administrativa dos municípios, por meio do Plano de Ação de Atualização das Divisas Intermunicipais (BAHIA, 2011; SEI, 2019b), a qual não possui consenso entre representantes políticos, moradores e técnicos.

O volume de empreendimentos estimulados por meio do Programa de Aceleração do Crescimento (PAC), especialmente, o Programa Minha Casa, Minha Visa (PMCMV), por sinal, incorreu em profundos impactos tanto em Feira de Santana quando nas pequenas cidades, fato que também influenciou a expansão urbana, bem como dinâmicas de periferização, pobres e de status. Em áreas urbanas menores, isso é um fenômeno relativamente recente na lógica da urbanização da Bahia.

Outro aspecto para compreender a dinâmica urbana atual do Portal do Sertão é avaliar a centralidade exercida pelas áreas urbanas que o compõem. Os estudos realizados pelo IBGE (2008), intitulados Regiões de Influências das Cidades (REGIC), ao analisar a rede urbana brasileira, classificaram Feira de Santana como Capital Regional de nível B, a qual polarizava 47 cidades, e as demais foram consideradas como Centros Locais. Todavia, análises realizadas por Leniara e Santos (2017) e Santana (2017) consideram que Irará e Santo Estevão apresentam pequena centralidade em relação a municípios menores circunvizinhos (Figura 7). 
Figura 7- Rede Urbana do Território de Identidade Portal do Sertão, Bahia, 2019
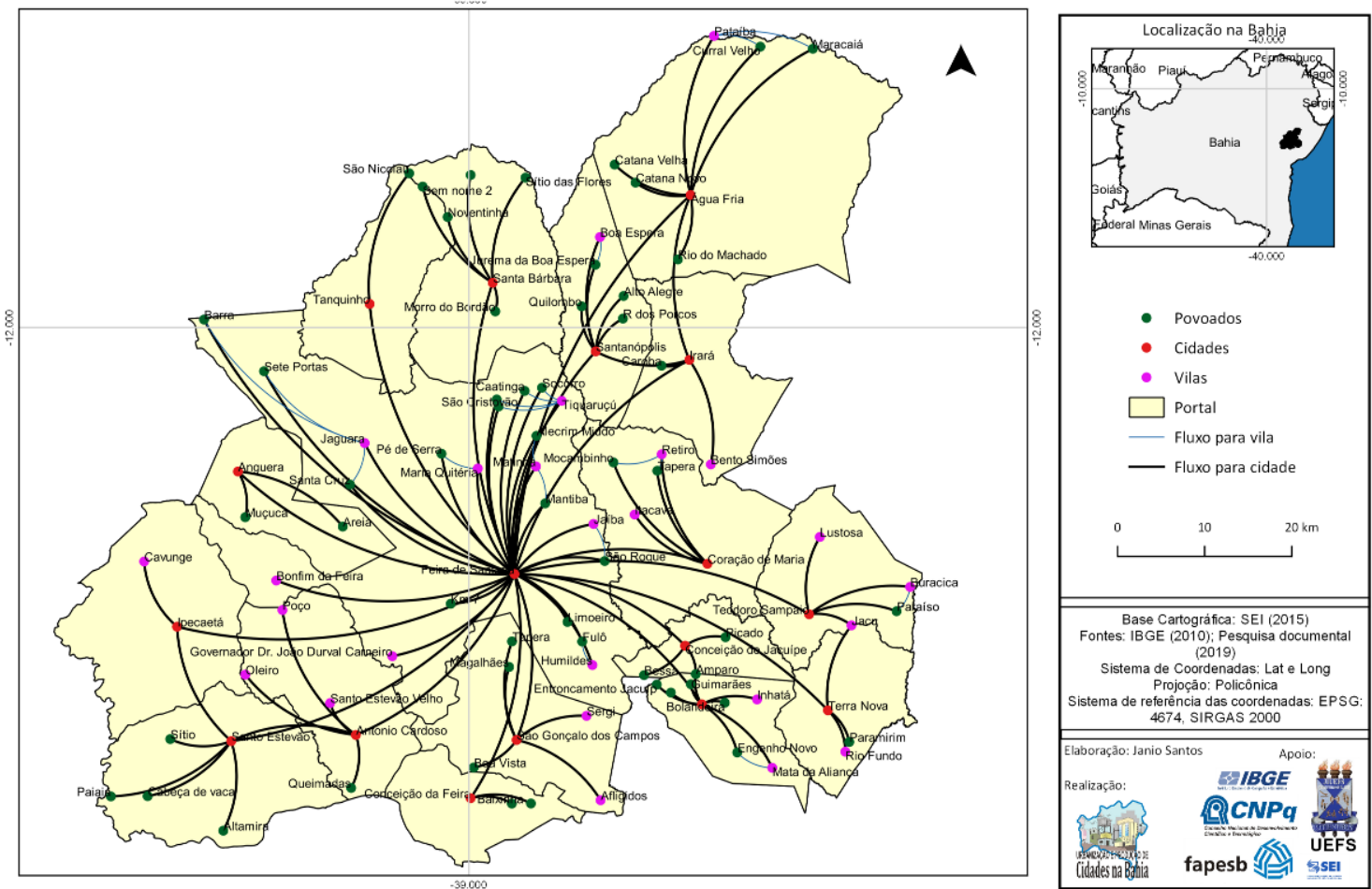

Do exposto, nota-se que no século XXI o padrão demográfico corrobora a consolidação da dinâmica urbana no Portal do Sertão como algo inexorável e significa a virtual tendência à constituição de uma sociedade urbana (LEFEBVRE, 2004, 2008), sem que, necessariamente, isso signifique o desaparecimento integral e completo do modo de vida rural. O crescimento geométrico anual da população urbana arrefeceu, sobretudo, se comparado às décadas anteriores, mas mantem-se positivo em quase todas as cidades, e permanece a tendência de decréscimo da população rural na maioria dos municípios. Também se confirma o aumento da participação da população urbana sobre a total, isso dentro dos critérios estabelecidos pelo IBGE, o que reflete em taxas de urbanização maiores.

No que concerne à expansão das áreas urbanas do Portal do Sertão, entre 2000 e 2016, observa-se que a maioria das cidades, vilas e povoados cresceu territorialmente. Como já mencionado, o êxodo rural e o fortalecimento da industrial da construção civil, esse último aliado, sobretudo, aos interesses dos incorporadores imobiliários, são os fatores que mais influenciam tal tendência. Diferente do que certas concepções reducionistas e acríticas apontam, não é o 
crescimento urbano, per si, que decorre na intensificação da periferização, fenômeno que, contraditoriamente, também se acentua, sobretudo, nas cidades citadas como mais dinâmicas.

Outra tendência verificada e que demarca bastante as mudanças no fenômeno da urbanização no século XXI é, por um lado, a constituição de áreas urbanas mais dispersas, o que, por outro lado, aponta para dissolução das diferenças entre os espaços rurais e urbanos, no sentido da dificuldade em distinguir onde começa o campo e termina a cidade. Autores como Sposito (2009) entendem que esse fato refere-se à constituição, no período atual, de uma urbanização difusa, que resulta em formas urbanas mais dispersas. Contudo, na região em estudo, nem sempre isso se realiza por interferência direta do setor imobiliário, como regularmente analisado, pois também relaciona-se à integração de antigos aglomerados rurais às cidades, por efetivo da promulgação de lei ou face à construção de conjuntos residenciais.

Ainda assim é importante não generalizar tais aspectos para todas as áreas urbanas, como se a tendência ao crescimento fosse algo inexorável. Os dados do Censo de 2010 apontam, na contramão disso, que houve redução na população de alguns núcleos, isso comparado se com dados de 2000, tais como a cidade de Teodoro Sampaio, em -7,90\%, e cinco vilas: Mata da Aliança e Inhatá, Amélia Rodrigues, em respectivamente, $-36,95 \%$ e -2,49\%; Afligidos, São Gonçalo dos Campos, em -8,29\%; Jaguara, Feira de Santana, em -4,59\%; e Buracica, Teodoro Sampaio, em -8,47\% (IBGE, 2010).

As alterações sobreditas atestam que o conteúdo da urbanização foi profundamente transformado, como foram modificadas às próprias estruturas e relações das/nas áreas urbanas. A articulação delas no Portal do Sertão com as demais regiões do Brasil e do mundo também se dá por redes que vão além, no sentido de superar, o nível físico-espacial e compõe um espaço virtual, sem que necessariamente elimine as lógicas espaciais, pois determinadas relações urbanas ainda são constituídas por elos fortemente físico-territoriais. Isso 
significa maior densidade em componentes técnicos e a alteração de práticas e da capacidade de circulação e comunicação entre pessoas, o que redunda na coexistência entre redes hierárquicas e redes heterárquicas (CATELAN, 2013), algo que é assaz diferente do que ocorreu na década de 1950. Todavia, isso não anula a existência de formas novas de desigualdades, seja porque: não há participação de todos de forma igual na rede, seja essa hierárquica ou heterárquica; a própria lógica do sistema é estruturalmente excludente; e a concentração da renda é massiva, o que torna a "inclusão" de vários segmentos sociais nessas redes assaz precária, isso quando ocorre.

Na escala intraurbana, verifica-se o aprofundamento das desigualdades entre as classes, materializado na divisão territorial, social e técnica do trabalho, pela constituição de novos espaços residenciais e equipamentos urbanos relativamente mais sofisticados, em contraposição à ampliação de espaços precários, o que fortalece a separação entre ricos e pobres. Também se percebe que os conteúdos dos centros, subcentros e das periferias urbanas passaram por transformações e, por sua vez, influenciaram em novas lógicas na estrutura urbana. E assim, as cidades, vilas e povoados do Portal do Sertão conformam-se como novos elos na urbanização: entre rural e urbano, local e global, e simbólico e material.

\section{CONSIDERAÇÕES FINAIS}

A interpretação sobre a urbanização permite considerar processos que ocorrem entrelaçados em várias escalas, desde a produção do espaço mundial às formas mais genuínas do viver em pequenos núcleos urbanos. Isso é enredado por meio da compreensão sobre as transformações políticas, econômicas e sociais que ocorreram e ocorrem em dada unidade territorial. Portanto, analisar as nuanças que explicam a urbanização permite verificar, em temporalidades e espacialidades distintas, como imperativos da sociedade incidem sobre a 
produção de aglomerados de pessoas, os quais podem ser categorizados como cidades, vilas e outros núcleos (urbanos ou não) menores.

No caso do Território de Identidade Portal do Sertão, os marcos do processo de urbanização atravessaram muitos séculos. Datados dos primórdios do Período Colonial, quando da invasão e, sobretudo, ocupação das terras ao sul do denominado continente americano, passaram pelos séculos XIX e XX até atingirem a lógica atual. Nesse percurso, constituíram-se áreas urbanas importantes, moldadas ao longo do tempo por fatores conjunturais e estruturais, os quais atraíram pessoas, fluxos e capitais de origens diversas, adquiriram identidades e ganharam relevo nos enlaces entre as particularidades da região e as determinantes globais.

Da composição de um número pequeno de cidades e vilas existentes no Portal do Sertão até o século XIX, viu-se o florescer de aglomerados pueris no século $X X$, os quais foram berços de inúmeras pequenas cidades e vilas, a maioria existente nos dias atuais. Todavia, a abertura de meios de circulação e, sobremodo, o processo de industrialização ocorrido a partir da década de 1940 fizeram com que tais núcleos urbanos alterassem seus conteúdos e formas, ao passo que produziram novas tramas tanto na dinâmica das cidades, vilas e povoados, quanto na vida de quem delas fez e faz parte.

Ao analisar o processo de urbanização, com recorte para o Portal do Sertão, nota-se que ao passo que as cidades fortaleceram seus papeis na reprodução das relações capitalistas, mediadas pelo avanço dos interesses de grupos econômicos que controlam a produção, e daqueles que lutam para vender a força de trabalho, tornam mais evidentes as precárias condições de vida dos trabalhadores, a segregação socioespacial, a expansão do tecido urbano etc. Isso é bem evidente em Feira de Santana, São Gonçalo dos Campos e Conceição do Jacuípe, cidades cuja dinâmica econômica é mais pujante e onde as alterações no conteúdo do urbano tornaram-se mais evidentes. Em contraponto às pequenas cidades e vilas que se localizam fora desse eixo, considerado de maior 
"desenvolvimento", cujas marcas do urbano são fortemente entrelaçadas e, por vezes, determinadas, pelo modo de vida rural.

Se, por um lado, todos esses determinantes impõem a sociedade urbana, aquela germinada no bojo do Capitalismo, como horizonte virtual pretendido e, dessa forma, esgarça modos de vidas pretéritos, sobretudo aqueles conteúdos conexos às experiências e relações que não estejam ou sejam subjugadas à ordem imposta; por outro, como o processo é contraditório, isso nunca se realiza por completo sob o prisma da urbanização integral do território, o que exige a leitura sobre outros elementos como determinantes da produção dos espaços urbanos no contexto atual.

\section{REFERÊNCIAS}

BAHIA, Lei n 12.057, de 11 de janeiro de 2011. Dispõe sobre a Atualização das Divisas Intermunicipais do Estado da Bahia, e adota providências correlatas. Disponível em: http://www.legislabahia.ba.gov.br/documentos/lei-no-12057-de-11-de-janeiro-de2011, 10 mar. 2019.

BAHIA, Secretaria de Planejamento (SEPLAN). 2013. Territórios de Identidade: Mapa. Disponível em: http://www.seplan.ba.gov.br/territorios-de-identidade/mapa, acesso: 10 mar. 2019.

BRASIL. Decreto-Lei de 2 de março de 1938. Dispõe sobre a divisão territorial do país, e dá outras. Disponível em: http://www2.camara.gov.br/legin/fed/declei/19301939/decreto-lei-311-2-marco-1938-351501-publicacaooriginal-1-pe.html, acesso: 10 mar. 2019.

CATELAN, M. J. Heterarquia urbana: interações espaciais interescalares e cidades médias. São Paulo: Cultura Acadêmica, 2013

FEDERAÇÃO DAS INDÚSTRIAS DO ESTADO DA BAHIA (FIEB). Guia Industrial do Estado da Bahia. Disponível em: http://www.fieb.org.br/guia, acesso: 10 mar. 2019.

FREITAS, N. B. Modernização Industrial em Feira de Santana: Uma análise da implantação do Centro Industrial do Subaé - CIS. Sitientibus, n. 41, 2009, p. 139-160

INSTITUTO BRASILEIRO DE GEOGRAFIA E ESTATÍSTICA (IBGE). Censo Demográfico: população e habitação, 1940. Parte XII, tomo I, série regional. Rio de Janeiro: IBGE, 1950. 
INSTITUTO BRASILEIRO DE GEOGRAFIA E ESTATÍSTICA (IBGE). Censo Demográfico: Estado da Bahia, 1950. V. XX, tomo I. Rio de Janeiro: IBGE, 1955.

INSTITUTO BRASILEIRO DE GEOGRAFIA E ESTATÍSTICA (IBGE). Enciclopédia dos Municípios Brasileiros (Coord. e Plan. Jurandyr Pires Ferreira) Rio de Janeiro: IBGE, 1958a (Volumes XX).

INSTITUTO BRASILEIRO DE GEOGRAFIA E ESTATÍSTICA (IBGE). Enciclopédia dos Municípios Brasileiros (Coord. e Plan. Jurandyr Pires Ferreira) Rio de Janeiro: IBGE, 1958b (Volumes XXI).

INSTITUTO BRASILEIRO DE GEOGRAFIA E ESTATÍSTICA (IBGE). Brasil: Sinopse Preliminar do Censo Demográfico, 1960. Rio de Janeiro: IBGE, 1960.

INSTITUTO BRASILEIRO DE GEOGRAFIA E ESTATÍSTICA (IBGE). Censo Demográfico Bahia: recenseamento geral, 1970, v. 1, tomo XIII. Rio de Janeiro: IBGE, 1973.

INSTITUTO BRASILEIRO DE GEOGRAFIA E ESTATÍSTICA (IBGE). Censo Demográfico 1980: dados distritais-Bahia, v. 1, tomo 3, n. 13. Rio de Janeiro: IBGE, 1983,

INSTITUTO BRASILEIRO DE GEOGRAFIA E ESTATÍSTICA (IBGE). Censo Demográfico 1991: resultados do universo relativos às características da população e dos domicílios, n.17-Bahia Rio de Janeiro: IBGE, 1991.

INSTITUTO BRASILEIRO DE GEOGRAFIA E ESTATÍSTICA (IBGE). Censo Demográfico, 2000. Disponível em: http://www.sidra.ibge.gov.br, acesso: 10 mar. 2019.

INSTITUTO BRASILEIRO DE GEOGRAFIA E ESTATÍSTICA (IBGE). Regiões de influência das cidades (REGIC), 2007. IBGE: Rio de Janeiro, 2008. Disponível em: http://www.ibge.gov.br/home/geociencias/ geografia/regic.shtm,. Acesso em: 10 mar. 2019.

INSTITUTO BRASILEIRO DE GEOGRAFIA E ESTATÍSTICA (IBGE). Censo Demográfico, 2010. Disponível em: http://www.ibge.gov.br/censo2010,.Acesso em: 10 mar. 2019.

INSTITUTO BRASILEIRO DE GEOGRAFIA E ESTATÍSTICA (IBGE). Levantamento Sistemático da Produção Agrícola. IBGE, 2017. Disponível em: https://www.ibge.gov.br/estatisticas-novoportal/economicas/agricultura-epecuaria/9201-levantamento-sistematico-da-producao-agricola.html?=\&t=o-que-e, Acesso em: 10 mar. 2019.

INSTITUTO BRASILEIRO DE GEOGRAFIA E ESTATÍSTICA (IBGE). Redes e fluxos do território: ligações rodoviárias e hidroviárias, 2016. Rio de Janeiro: 2017. Disponível em: https://www.ibge.gov.br/apps/ligacoes_rodoviarias/. Acesso em: 27 out. 2017. 
INSTITUTO BRASILEIRO DE GEOGRAFIA E ESTATÍSTICA (IBGE). Cidades. Disponível em: https://cidades.ibge.gov.br/, Acesso em: 10 mar. 2019.

LEFEBVRE, H. A revolução urbana. Belo Horizonte: Editora URMG, 2004.

LEFEBVRE, H. Espaço e Política. Belo Horizonte: Editora URMG, 2008.

MOREIRA, S. O.; SANTOS, J. Mobilidade e plasticidade do trabalho: reflexões teóricas. Revista Pegada Eletrônica (Online), v. 19, 2018, p. 316-346

MUMFORD, L. The city in history: its origins, its transformations, and its prospects. Harcourt, Brace \& World, 1961

SANTANA, I. M. A feira livre no contexto do desenvolvimento urbano da cidade de Irará- BA. In: CONGRESO INTERNACIONAL DE GEOGRAFÍA URBANA, 2, Anais..., Lujan, Argentina, 2017

SANTOS, J. A natureza contraditória da urbanização em um contexto de maior complexidade na produção das cidades baianas. In: HENRIQUE, Wendel.; LOPES, Diva F. Cidades médias e pequenas: teorias, conceitos e estudos de caso. Salvador: SEl, 2010, p. 50-76.

SANTOS, J. A cidade poli(multi)nucleada: a reestruturação do espaço urbano em salvador. Salvador: EDUFBA, 2013.

SANTOS, M.A urbanização brasileira. São Paulo: HUCITEC, 1993.

SILVA, L da C. A produção do espaço urbano nas cidades pequenas: um estudo de caso sobre a cidade de Santo Estevão-BA. In: CONGRESO INTERNACIONAL DE GEOGRAFÍA URBANA, 2, Anais..., Lujan, Argentina, 2017

SPOSITO, M. E. B. Capitalismo e urbanização. 8ª ed. São Paulo: Contexto, 1996

SPOSITO, M. E. B. O chão em pedaços: urbanização, economia e cidades no Estado de São Paulo, 2004. 504f. Tese (Livre Docência)-Faculdade de Ciências e Tecnologia, Universidade Estadual Paulista, Presidente Prudente.

SPOSITO, M. E. B. Urbanização difusa e cidades dispersas: perspectivas espaçotemporais contemporâneas. In: REIS, N. G. Sobre dispersão urbana. São Paulo: Via das Artes, 2009. p. 38-54

SUPERINTENDÊNCIA DE ESTUDOS ECONÔMICOS E SOCIAIS DA BAHIA (SEI). Povoados da Bahia: 1980 a 2000. Disponível em:

http://www.sei.ba.gov.br/index.php?option=com_content\&view=article\&layout=edit\&i $d=176 \&$ Itemid=188, acesso: 10 mar. 2019a. 
SUPERINTENDÊNCIA DE ESTUDOS ECONÔMICOS E SOCIAIS DA BAHIA (SEI). Limites Territoriais - Limites Municipais. Disponível em: http://www.sei.ba.gov.br/index.php?option=com_content\&view=article\&id=2617\&/tem $\mathrm{id}=537$, acesso: 10 mar. $2019 \mathrm{~b}$.

TEIXEIRA, C. Bahia: caminhos... Estradas... Rodovias... Notas para a história. Salvador: EGBA, 1998

ZORZO, F. A. As práticas de territorialização e a formação de uma rede urbana no Brasil: doze cidades conectadas pela Ferrovia no Sul do Recôncavo e Sudoeste da Bahia - 1870 - 1930, 19993, 326f. Tese (Doutorado em História da Arquitetura-História Urbana), Universitat Politécnica de Catalunya, Barcelona, 1999.

\footnotetext{
1 É essencial diferenciar a industrialização, enquanto um processo, da mera instalação de indústrias num dado território. Como expõe Sposito (1998), o primeiro refere-se dinâmicas mais amplas e caracteriza-se pela hegemonia da atividade industrial sobre as demais, que nem sempre se traduz em percentuais mais altos referentes ao Produto Interno Bruto (PIB) ou a ocupação, mas ao predomínio nas diretrizes da sociedade, economia e política em um dado território. Assim, pode haver instalações de indústrias, como ocorreu no Brasil no século XIX, sem que necessariamente uma industrialização mais ampla e determinante ocorra.
}

${ }^{2}$ Neste texto, a área atual do Território de Identidade Portal do Sertão será sempre considerada para fins de análise.

${ }^{3}$ Os municípios de Água Fria e Irará tiveram mudanças de sede.

${ }^{4}$ A criação do município de Feira de Santana deu-se em 13 de novembro de 1832, fato confirmado pelos distritos que foram criados e anexados posteriormente (IBGE, 1958).

${ }^{5}$ São apenas seis cidades, apesar da área conter sete municípios. Isso ocorre porque uma parte pertencia a Santo Amaro, cuja sede não estava localizada na região em estudo.

${ }^{6}$ A Comissão Econômica para a América Latina e o Caribe (CEPAL) fundamentava-se no fato de que a lógica agroexportadora acentuava o abismo entre países pobres e ricos. A política de industrialização e modernização, com protecionismo estatal, era o caminho para os países pobres.

viiApenas foram mencionados os municípios que aparecem entre os dez maiores produtores do Estado da Bahia (IBGE, 2016) 